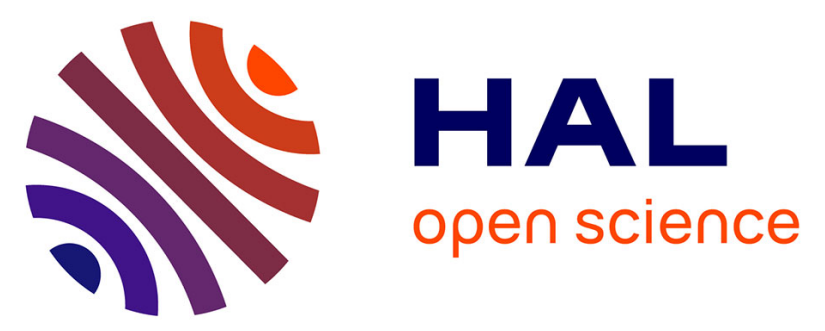

\title{
Effect of land use on interrill erosion in a montane catchment of Northern Laos: An analysis based on a pluri-annual runoff and soil loss database
}

J. Patin, E. Mouche, O. Ribolzi, O. Sengtahevanghoung, K.O. O Latsachak, B. Soulileuth, Vincent Chaplot, C. Valentin

\section{To cite this version:}

J. Patin, E. Mouche, O. Ribolzi, O. Sengtahevanghoung, K.O. O Latsachak, et al.. Effect of land use on interrill erosion in a montane catchment of Northern Laos: An analysis based on a pluri-annual runoff and soil loss database. Journal of Hydrology, 2018, 563, pp.480 - 494. 10.1016/j.jhydrol.2018.05.044 . hal-01839994

\section{HAL Id: hal-01839994 \\ https://hal.sorbonne-universite.fr/hal-01839994}

Submitted on 16 Jul 2018

HAL is a multi-disciplinary open access archive for the deposit and dissemination of scientific research documents, whether they are published or not. The documents may come from teaching and research institutions in France or abroad, or from public or private research centers.
L'archive ouverte pluridisciplinaire HAL, est destinée au dépôt et à la diffusion de documents scientifiques de niveau recherche, publiés ou non, émanant des établissements d'enseignement et de recherche français ou étrangers, des laboratoires publics ou privés. 


\title{
Effect of land use on interrill erosion in a montane catchment of Northern Laos: An analysis based on a pluri-annual runoff and soil loss database
}

\author{
J. Patin ${ }^{\mathrm{a}}$, E. Mouche ${ }^{\mathrm{a}, *}$, O. Ribolzi ${ }^{\mathrm{b}}$, O. Sengtahevanghoung ${ }^{\mathrm{c}}$, K.O. Latsachak ${ }^{\mathrm{d}}$, B. Soulileuth ${ }^{\mathrm{d}}$, \\ V. Chaplot ${ }^{\mathrm{e}}$, C. Valentin ${ }^{\mathrm{f}}$ \\ ${ }^{a}$ Laboratoire des Sciences du Climat et de l'Environnement, UMR 8212, C.E. de Saclay, Orme des Merisiers, F-91190 Gif-sur-Yvette, France \\ ${ }^{\mathrm{b}}$ Géosciences Environnement Toulouse, UMR 5563, Université Paul Sabatier, 14 Av. Edouard Belin, F-31400 Toulouse, France \\ ' Agriculture Land-Use Planning Center, Ministry of Agriculture and Forestry, Vientiane, Lao Democratic People's Republic \\ d Institut de Recherche pour le Développement, Ban Sisangvone, BP5992 Vientiane, Lao Democratic People's Republic \\ e Laboratoire d'Océanographie et du Climat, UMR 7159, Université Pierre et Marie Curie, 4 Pl. Jussieu, F-75005 Paris, France \\ ${ }^{\mathrm{f}}$ Institut d'Ecologie et des Sciences de l'Environnement de Paris, UMR7618, Université Pierre et Marie Curie, 4 Pl. Jussieu, F-75005 Paris, France
}

\begin{abstract}
A B S T R A C T
The introduction of cash crops and the evolution of farming practices in the uplands of Southeast Asia have drastically changed the agricultural landscape of the region during these last decades. This evolution has significantly increased soil erosion leading to important on and off-site effects. A long-term multi-scale monitoring of soil erosion was initiated in the early 2000's in the Houay Pano catchment located near the city of Luang Prabang in Northern Laos to assess these effects and propose sustainable land management solutions. We report here the analysis and the modelling of the soil erosion measurements made during the whole period on $1 \mathrm{~m}^{2}$ plots for different land uses. As expected, land use has an important impact on runoff production and soil erosion. The mean annual runoff coefficient increased from 0.05 for established fallow ( 4 years) to 0.45 for old teak trees plantation (14 years) with intermediate values for crops. The mean soil loss followed the same trend with respect to land use, from $25 \mathrm{~g} \mathrm{~m}^{-2} \mathrm{y}^{-1}$ to $3765 \mathrm{~g} \mathrm{~m}^{-2} \mathrm{y}^{-1}$. These measurements confirm that established fallow promotes infiltration and reduces erosion and, at the opposite, teak tree increases soil crusting, lowers the infiltration rate and enhances soil detachment. The splash and wash erosion component of a process-oriented model developed for terrace erosion was used. This model describes the soil loss after a rainfall event as the product of an effective soil detachability, the rainfall kinetic energy, the runoff coefficient and different attenuation factors linked to soil surface features. The agreement is good, both at the event and the yearly scales. When aggregated by land use, surface features percentages have low standard deviations and soil detachability variability may be described by a log-normal distribution. This suggests that each land use has a unique signature in the erosion process given by the percentages and the distribution. We conclude that: (i) leaving the litter layer and an understorey in crops and trees plantations is the best way to minimize soil erosion, and (ii) the splash and wash model may be helpful to set up optimal agronomic strategies for a sustainable land use of Southeast Asia uplands.
\end{abstract}

\section{Introduction}

In the sloping lands of Southeast-Asia, soil erosion is a pressing environmental issue (Bruijnzeel, 2004; Sidle et al., 2006). The factors of erosion are known and numerous: steep and long slopes, heavy storms, agricultural practices such as shifting cultivation with short fallow periods, conversion of the tropical rainforests to agriculture, cash crop cultivation and/or high-value hardwood plantations such as sugar cane, paddy rice, maize, cardamom, teak or rubber trees (Thongmanivong and Fujita, 2006; Sidle et al., 2006; Valentin et al., 2008; Ziegler et al.,
2009). Under Laotian conditions, slash and burn cultivation and shifting cultivation is a non intensive practice which preserves soil fertility when the fallow period exceeds ten years (Roder et al., 1997; Ducourtieux et al., 2006; Huon et al., 2013). It has been shown that infiltration properties of fallow, especially established fallow, are high and the sediment loss is quite low (Patin et al., 2012). The reduction to three or five years of the fallow period leads to an increase of runoff production and accordingly of soil erosion (Valentin et al., 2008). Deforestation leads to a rapid erosion of the topsoil organic matter, an increase of soil crusting, and therefore a decrease of rainfall infiltration

\footnotetext{
* Corresponding author.

E-mail addresses: jeremy.patin@lsce.ipsl.fr (J. Patin), emmanuel.mouche@lsce.ipsl.fr (E. Mouche), olivier.ribolzi@ird.fr (O. Ribolzi), vincent.chaplot@ird.fr (V. Chaplot), christian.valentin@ird.fr (C. Valentin).
} 


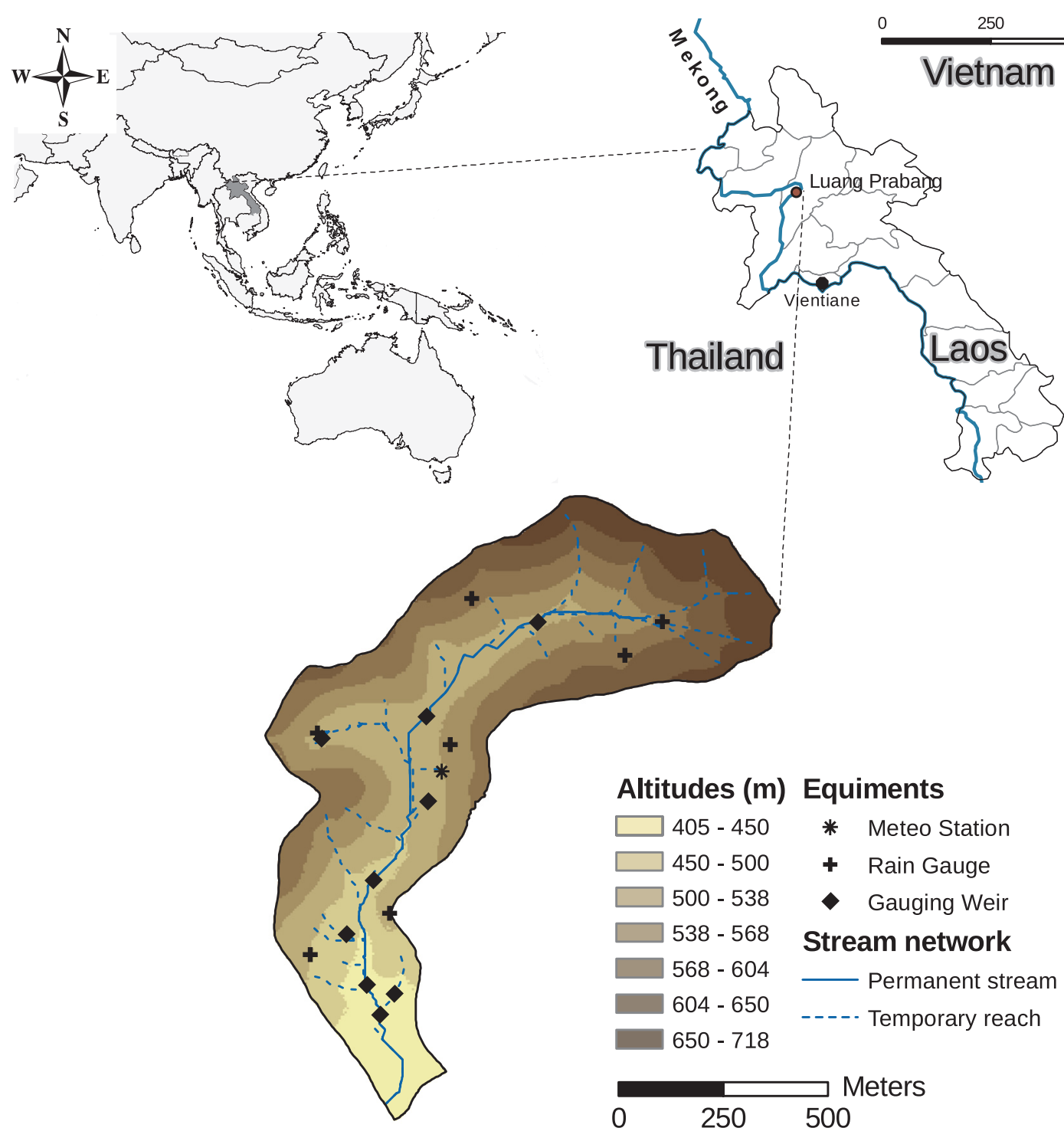

Fig. 1. Localization maps of the study site (Luang Prabang province, Lao PDR), elevation (DEM $10 \mathrm{~m} \times 10 \mathrm{~m}$ ) and localization of permanent equipments.

properties. This process enhances the production of surface runoff, overland flow and stream discharge, and, as a result, may foster bank erosion. In very steep areas, it may also induce a loss of soil stability which, combined with the absence of a stabilizing roots network, may lead to landslides (Sidle et al., 2006; Ziegler et al., 2009). Afforestation with hardwood plantation, such as teak tree, may also trigger erosion if the soil is left bare with no understorey or ground cover (Hall and Calder, 1993; Nanko et al., 2015; Ribolzi et al., 2017). The main on-site effects of these land use changes are: a soil degradation, a decrease of soil moisture and its consequences on crops development during drought periods, and a fostered runoff production which makes interrill erosion very active (Sidle et al., 2006; Valentin et al., 2008). The hydrological consequences are the formation of flash floods during storm events and an insufficient aquifer recharge during the humid season leading to anomalous low flow rates during the dry season (Bruijnzeel, 2004; Sidle et al., 2006; Lacombe et al., 2016). The export of sediment in the stream network leads to the well known siltation of water reservoirs and water bodies. Suspended matter is also a vector of chemical and biological contaminants and contributes to the degradation of water quality (Ribolzi et al., 2011; Causse et al., 2015).

In order to assess these environmental issues on the long term, to provide data at the different scales of interest and propose sustainable agricultural practices, a regional network of sites called MSEC (multi- scale environmental changes) was launched in 1998 ( http://msec.obsmip.fr). At the present time, three countries (Thailand, Lao PDR, Vietnam) participate in the network. The overall objective of this network is to study the impact of land use change on water and sediment transfers, and on soil and water quantity and quality. The Lao site considered in this work is a small agricultural catchment, Houay Pano catchment, located in North Laos, $10 \mathrm{~km}$ from the city of Luang Prabang. This catchment has no uniform cover but a mosaic of cropland and more or less natural vegetation. Erosion is studied at different scales, from the interrill scale to the catchment scale, via the subcatchment scale (Chaplot et al., 2007; Chaplot and Poesen, 2012; Huon et al., 2017). Results obtained from fallout radionuclides measurements show that $70-80 \%$ of the total sediment load measured in the upper part of the watershed comes essentially from interrill erosion (Evrard et al., 2016). Interrill erosion is investigated mainly at the micro-plot scale of $1 \mathrm{~m}^{2}$, under simulated and natural rainfall, and for different land covers. At this scale, the dominant erosion mechanism is splash and sediments are washed, i.e. transported, by runoff (Kinnell, 2005). Depending on their diameter, some sediments may settle within the micro-plot, some others, too small, will travel outside the plot. At the micro-plot scale, the erosive power of runoff is not high enough to detach particles. The travel length of runoff along the slope must be longer, at least a few meters, to obtain a runoff depth and consequently 
a stream power sufficient to observe rill erosion (Hairsine and Rose, 1991; Nord and Esteves, 2005). Splash and wash processes have been rarely isolated and investigated in the field in natural conditions (natural soil and rainfall, given land use) and over a long period as in Houay Pano catchment. In most of the cases of the literature, the scales of investigation are such that interrill and rill erosion processes are observed and modelled simultaneously (Van Dijk and Bruijnzed, 2004a; Nord and Esteves, 2005). When the scale of investigation is metric, the splash and wash processes are often studied in laboratory on soil trays filled with bare soil and under simulated rainfall. (Van Dijk et al., 2002b; Kinnell, 2005; Furbish et al., 2007; Zhang and Wang, 2017). Some outdoor experiments have been performed under simulated or natural rainfall but generally in experimental conditions different from the natural conditions, and/or over a short period (i.e. a few stormy events), or at a scale larger than the micro-plot (Chaplot and Le, 2000; Van Dijk et al., 2002b; Van Dijk et al., 2003; Ribolzi et al., 2011; Villatoro-Sánchez et al., 2015; Fang et al., 2017). On the experimental site of Houay Pano, erosion and soil carbon redistribution were studied on different micro-plots of $1 \mathrm{~m}^{2}$ and under natural conditions, but during one or two years periods only (Chaplot et al., 2007).

This work analyzes the runoff production and the soil losses measured from $1 \mathrm{~m}^{2}$ plots installed each year during a 13-years survey, on the period 2002-2016 with the exception of 2012 and 2015, in various conditions of Houay Pano catchment. The overall objective is to quantify the effect of each vegetation cover on the erosion rate at the micro-plot scale and the yearly scale, to identify the main environmental factors influencing erosion, and finally to propose a model capable to encompass all the results. For this purpose, we follow the methodology and the splash and wash component of the erosion model developed by Van Dijk and Bruijnzeel (2004b) to analyze runoff and soil loss from bench terraces in West Java.

\section{Material and methods}

\subsection{Site}

The experimental site is located in Northern Lao PDR, $10 \mathrm{~km}$ south of Luang Prabang city (Fig. 1). The 62 ha catchment is a second order tributary of the Mekong river. It is a typical south-east Asia catchment undergoing a slash and burn system with diminishing fallow periods and an increase of cash-crops growing areas (maize, Job's tear) and teak tree plantations over the years (Lacombe et al., 2016; Ribolzi et al., 2017). Fig. 2 shows the land use map of 2007. Elevation ranges from $400 \mathrm{~m}$ to $720 \mathrm{~m}$ and slopes are steep, from $2 \%$ to more than $110 \%$ with a mean slope of $52 \%$. The climate is a wet-dry monsoon climate with an average annual rainfall of $1300 \mathrm{~mm}$ of which $80 \%$ occurs during the rainy season from mid-May to mid-October. The geologic substrate is argillite, siltstone and fine-grained sandstone from Permian to Upper Carboniferous Periods. The soils developed on these bedrocks are loamy. They are mainly Entisol, Ultisol and Alfisol (in the US Taxonomy soil classification system) that respectively cover 20,30 and $50 \%$ of the catchment. Soil thickness decreases from a few meters (up to $4 \mathrm{~m}$ ) to a few tens of centimetres in the uphill direction (Chaplot et al., 2005).

\subsection{Micro-plots}

From 2002 to 2016, with the exception of 2012 and 2015, a total of 257 runoff collecting plots of $1 \mathrm{~m}^{2}$ has been installed in Houay Pano catchment. Each plot was established prior to the rainy season and operated for the whole season, and then removed for most of them. The plots were $1 \mathrm{~m}^{2}$ metal frame inserted into the soil at a depth of approximately $10 \mathrm{~cm}$ (Fig. 3). Care was taken not to disturb the plot soil surface. Runoff water was collected in a buried bucket with tap and the runoff amount was measured after each main rainfall event. The runoff aliquot was oven-dried to estimate the sediment concentration. The runoff measurements dataset between 2003 and 2009 have been

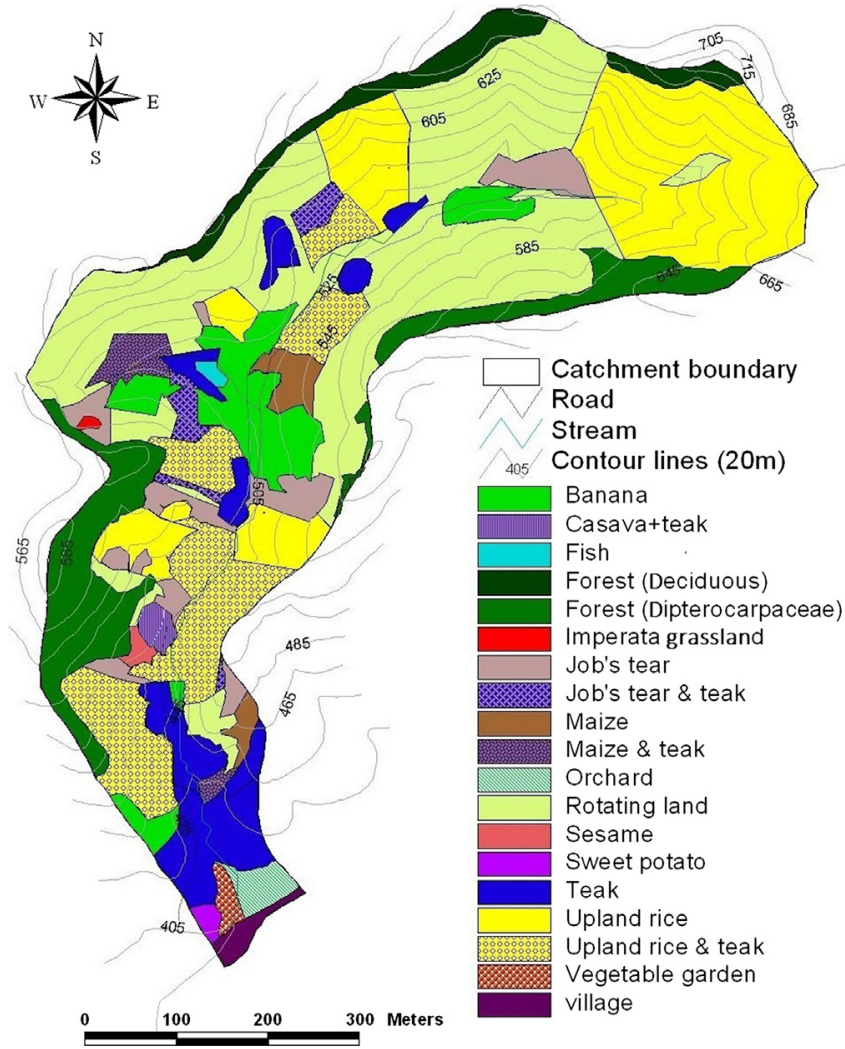

Fig. 2. Houay Pano catchment, land use map in 2007.

described and analysed in Patin et al. (2012). The rainfall rate was recorded by an automatic meteo station located in the watershed (Fig. 1), including a $0.1 \mathrm{~mm}$ tipping bucket raingauge. The sequence of tipping times was reprocessed after each rainfall with a constant time step of $6 \mathrm{~min}$. The minimal recorded rainfall intensity was therefore $1 \mathrm{~mm} \mathrm{~h}^{-1}$.

A wide variety of slopes, from $10 \%$ up to $110 \%$, and land uses (bare soil in the open, fallow, agricultural and forest crops of different ages) were investigated (Table 1). For example, in 2003 Table 1 indicates that two land uses, Job's tears and 40 years secondary forest, were studied on plots with a range of slopes lying between $10 \%$ and $65 \%$. In Table 1 jatropha crops and teak trees are each divided into young and old populations according to a limit age of 3 years for the first land use and 4 years for the second. The mean age of jatropha is 4.3 years and that of teak trees 14.6 years.

Soil surface conditions have been characterized twice a year on each plot at the onset of the rainy season (July) and during late monsoon (September). The methodology was first proposed by Casenave and Valentin (1992) and frequently used since then. The main surface types included weed cover, plant residues, charcoal, free aggregates and free gravel (i.e. not embedded in a crust) and three types of crust. In these soils, structural crusts result from the high packing of highly stable micro-aggregates (Ribolzi et al., 2011) and are gradually transformed into erosion crust as a result of the compacting impact of cumulative kinetic energy of raindrops and the smoothening effect of runoff. Erosion crusts are characterized by a thin and very compacted smooth plasmic layer (Valentin and Bresson, 1992). Unlike free gravel, gravel crust is made of gravel embedded in a structural or erosion crust (Valentin and Casenave, 1992). Weed cover not only considers the areal percentage of weeds in cropped plots, but also the low vegetation which is not planted, namely the understorey under teak trees. Residues include crop residues and also leaves, fallen twigs and branches. 


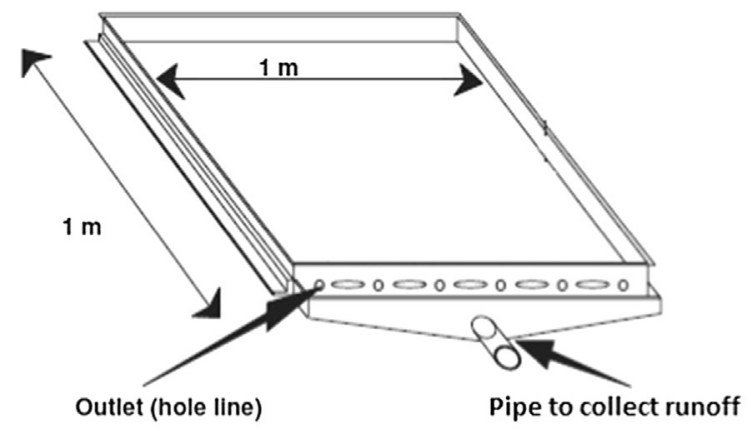

(a)

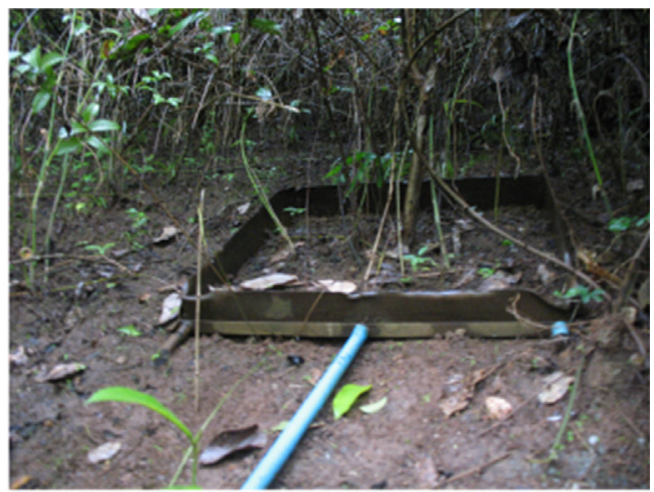

(b)

Fig. 3. $1 \mathrm{~m}^{2}$ plot. (a) Design sketch and (b) plot under fallow.

Table 1

Land use and slope characterization of the $2541 \mathrm{~m}^{2}$ study plots that were operated in the Houay Pano catchment between 2002 and 2016 plus the associated number of rainfall events for which runoff and erosion were measured.

\begin{tabular}{lllll}
\hline Year & Land uses $^{+}$ & Plots & Rainfall events & Slope (\%) \\
\hline 2002 & JT, Fo, Ri, Ma & 15 & 34 & $45-45$ \\
2003 & JT, Fo & 15 & 29 & $10-65$ \\
2004 & Fa1, Fo & 7 & 22 & $10-55$ \\
2005 & Fa2, Ri, Br, Te & 24 & 14 & $10-75$ \\
2006 & Pa, Ri, Ba, Gr, Br & 25 & 15 & $23-110$ \\
2007 & Ja0S, Te, Te2, PM & 30 & 15 & $18-64$ \\
2008 & Fa4, Fa1, Ri, Fa3, Ja, Ja1C, Te, Ja1S, & 30 & 23 & $30-69$ \\
& Fa2 & & & \\
2009 & Ja2C, Ja, Te, Ri, Fa3, Ja2S, Fa1, Fa2, & 30 & 20 & $30-69$ \\
& Fa4 & & & \\
2010 & Ja3S, Ja, Ja3C, Ofa & 18 & 19 & $20-69$ \\
2011 & Ofa & 9 & 24 & $20-69$ \\
2013 & Te & 6 & 35 & $46-53$ \\
2014 & Fa2, Te, Ri, Gr, Fo & 24 & 20 & $17-82$ \\
2016 & Te, Te4, BG & 18 & 32 & $40-65$ \\
\hline
\end{tabular}

$+\mathrm{Ba}=14-\mathrm{yr}$ Banana, $\mathrm{BG}=$ Broom Grass, $\mathrm{Br}=$ Bare, Fa1 $=1$-yr Fallow, Fa2 $=2$-yr Fallow, Fa3 $=3$-yr Fallow, Fa4 $=4$-yr Fallow, Fo $=40$-yr Secondary Forest, $\mathrm{Gr}=$ Grass, Ja0S $=0$-yr Jatropha Seed, Ja1C $=1$-yr Jatropha Cut, Ja1S = 1-yr Jatropha Seed, Ja2C = 2-yr Jatropha Cut, Ja2S = 2yr Jatropha Seed, Ja3C $=3$-yr Jatropha Cut, Ja3S $=3-y r$ Jatropha Seed, $\mathrm{Ja}=$ Jatropha $>3$-yr, JT $=$ Jobs tears, Ma $=$ Maize, Ofa $=40$-yr Old Fallow, Or $=25$-yr Orchard, $\mathrm{Pa}=11$-yr Bamboo, $\mathrm{PM}=$ Paper Mulberry, Ri $=$ Upland Rice, $\mathrm{Te} 2=2$-yr Teak tree, Te4 $=4$-yr Teak tree, $\mathrm{Te}=$ Teak tree $>4$-yr.

\subsection{Erosion model}

At the interrill scale, erosion is mainly driven by rainfall. Runoff depth, which is generally less than $1 \mathrm{~cm}$, is too low to induce flow driven erosion. At this scale, rain splash erosion is the main soil detachment process and the detached soil particles are transported by runoff (Kinnell, 2005; Nord and Esteves, 2005; Yu, 2005). We followed here the model, called TEST, developed by Van Dijk et al. (2003) and Van Dijk and Bruijnzed (2004a,b) to analyze runoff and soil loss under natural rainfall on bench terraces in West Java. For a given land use, the total soil loss during a rainfall event is modelled in TEST as $M=c_{w} Q$, where $M\left(\mathrm{~kg} \mathrm{~m}^{-2}\right)$ and $c_{w}\left(\mathrm{~kg} \mathrm{~m}^{-3}\right)$ are respectively the mass and the concentration of washed sediment in the total runoff depth, and $Q(\mathrm{~m})$ the total runoff depth. The concentration of washed sediment is approximated as the ratio of the detachment rate $\mu\left(\mathrm{g} \mathrm{m}^{-2}\right)$ to the total rainfall depth $R$. It is also assumed that only a fraction $j$ of the detached sediment can reach the plot boundary, and this fraction is independent of the storm characteristics. Because of the experimental setup, we neglected pure splash transport. The plot frame acts as a barrier to splashed soil particles which could drop outside the frame, or inversely, from the outside into the frame. On very steep slopes, particles may pass over the frame and this process may induce a difference between the predicted and the observed soil loss (Planchon and Mouche, 2010). Nevertheless, inclusion in the model of a splash transport component, as proposed by Van Dijk and Bruijnzeel (2004b) in their bench terraces erosion model, would result in an over-fitting problem, i.e. with too many multiplicative unknowns. The soil loss during a rainfall event is therefore:

$M=c_{w} Q=j \frac{\mu}{R} Q=j \mu C_{r}$

where $C_{r}=Q / R$ is the runoff coefficient. As specified by Van Dijk and Bruijnzeel (2004b), the model derivation is pragmatic and the expression of the washed sediment concentration gives an upper limit of the concentration. This model does not describe the erosion dynamics during the storm and some processes are disregarded. Nevertheless, it relies on a few parameters only which can be easily calibrated if the volume of data is sufficient. The system described by the model may be conceptualized as a bucket filled with soil in its bottom and rainfall filling the bucket. Soil detachment is constant during the rainfall event and sediment concentration is homogenized in the rainfall depth. At the end of the event, a fraction $C_{r}$ of the volume may flow out of the bucket. According to observations of splash erosion, the detachment rate $\mu$ depends linearly on the rainfall event kinetic energy $E\left(\mathrm{~J} \mathrm{~m}^{-2}\right): \mu=d E$ where $d$ is the soil detachability $\left(\mathrm{kg} \mathrm{J}^{-1}\right)$. If we call $D=j d$ the effective soil detachability, the total soil loss after a rainfall event reads:

$M=D E C_{r}$

In order to take into account the protecting effect of mulch and vegetation on the soil erosion of bench terraces Van Dijk and Bruijnzeel (2004b) introduce attenuation factors in the eroded mass equation (Eq. (2)). Previous studies of runoff generation on the $1 \mathrm{~m}^{2}$ plots of the Houay Pano site showed that soil surface features have an important impact on the magnitude of the runoff coefficient (Patin et al., 2012). As it will be shown further in Section 3.2, they also have an impact on soil erosion. Accordingly, the eroded mass equation (Eq. (2)) with attenuation factors is:

$M=D E C_{r} \exp \left(-\gamma_{\text {var } 1} W_{\text {var } 1}\right) \exp \left(-\gamma_{\text {var } 2} W_{\text {var } 2}\right) \ldots$

where var1, var $2, \ldots$ are physical variables describing soil surface conditions (residues, crop cover, weed cover,...$), W_{v a r 1}$ the fraction of the plot area covered by var 1 and $\gamma_{\text {var } 1}$ a decay characteristic parameter.

Assuming a constant detachability and constant soil surface conditions for each plot, annual soil loss is finally expressed as:

$\Sigma M=D \Sigma\left(E C_{r}\right) \exp \left(-\gamma_{\text {var } 1} W_{\text {var } 1}\right) \exp \left(-\gamma_{\text {var } 2} W_{\text {var } 2}\right) \ldots$

where the sum $\Sigma$ is on all the events of the year. This assumption allows a linearization of Eq. (3) with respect to $D$ and a multiple linear regression model on the logarithm of Eq. (4): 


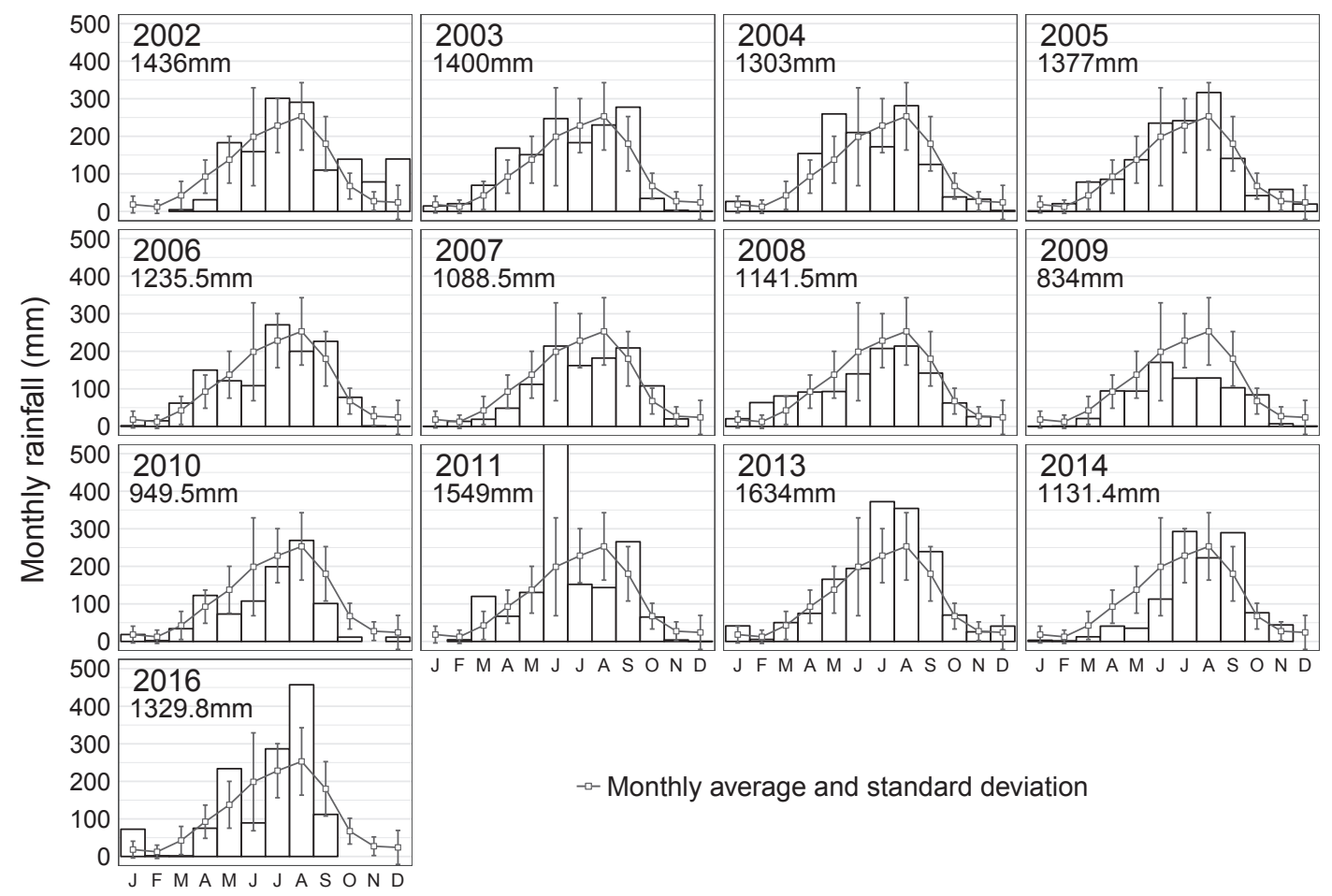

Fig. 4. Annual distributions of monthly rainfall, averaged monthly rainfall distribution and standard deviation for the period 2002-2016, and annual rainfall totals.

$\log (\Sigma M)=-\log (D)+\log \left(\Sigma E C_{r}\right)-\gamma_{\text {var } 1} W_{\text {var } 1}-\gamma_{\text {var } 2} W_{\text {var } 2 \cdots}$

\subsection{Rainfall kinetic energy and slope correction}

Field observations in Houay Pano showed that runoff production and soil detachment is much more intense under old teak trees $(>4$ years) than for any other land use. The soil under the teak trees is essentially bare with sparse understorey vegetation. This led to propose that teak trees produce, like other tree species such as the rubber tree, a throughfall kinetic energy higher than direct rainfall, i.e. unintercepted rainfall (Ribolzi et al., 2017; Liu et al., 2018). For this reason, the throughfall kinetic energy under teak tree of 14 years and the rainfall kinetic energy in the open have been measured with a disdrometer (RD 80). Following Kinnell (1981) and Van Dijk et al. (2002a), the rainfall kinetic energy content $e_{k}$ was modelled by the expression:

$e_{k}=e_{k \max }(1-a \exp (-b R))$

where $e_{k \max }$ denotes the maximum energy content and $a$ and $b$ are empirical constants. The total kinetic energy of a rainfall event was then expressed as:

$E=\Sigma\left(e_{k} R \Delta t\right)$

where the sum $\Sigma$ is on all the discretized times describing the rainfall event.

The relevant rainfall parameters such as the rainfall volume and the kinetic energy were corrected to account for the projected surface area $S$ of plots with steep slopes $\left(S=\cos (\alpha)\right.$ for a $1 \mathrm{~m}^{2}$ plot where $\alpha$ is the slope angle).

\subsection{Statistical methods}

Log-normal distribution is common when describing or simulating soil related variables. The probability density function of a log-normal distribution is: $f(x)=\frac{1}{\sqrt{2 \pi} \sigma_{y} x} \exp \left(\frac{-\left(\log (x)-\mu_{y}\right)^{2}}{2 \sigma_{y}^{2}}\right)$

where $\mu_{y}$ and $\sigma_{y}$ are respectively the mean and standard deviation of the logarithm $y=\log (x)$. The median and the geometric standard deviation of $x$ are $\mu_{x}=\exp \left(\sigma_{y}\right)$ and $\sigma_{x}=\exp \left(\mu_{y}\right)$ respectively. The interval $\left[\mu_{y} / \sigma_{y}, \mu_{y} \sigma_{y}\right]$ contains $68.3 \%$ of $y$ population as the interval $\left[\mu_{x}-\sigma_{x}, \mu_{x}+\sigma_{x}\right]$ does for $x$ (Limpert et al., 2001). When presenting results, $S D$ will refer to the usual standard deviation $\left(S D=\sigma_{y}\right)$, with an underlying normal or almost normal distribution assumption. When the underlying distribution is supposed to be log-normal or highly skewed, $G S D$ will refer to the geometric deviation $\left(G S D=\sigma_{x}\right)$.

To conduct a correlation analysis on the different physical variables of the system, the variables were first transformed to help them meet the distributional and variance assumptions required for linear models (Quinn and Keough, 2002). The type of transformation depends on the variable and the main objective of all the transformations was to make each distribution symmetrical. We made use of three types in this work. Variables expressed in percents were normalized using the arcsinus of the square root $y=\arcsin \sqrt{x}$. This is the classical transformation for percentages, especially when they are close to one or zero. The power transformation $y=x^{p}$, where $p<1$, is useful for right skewed distributions describing count data or size data. We used the square root function, which is applicable for mildly skewed distributions only. The third distribution is the log-normal distribution discussed previously and which is well suited to soil transfer variables such as infiltrability or hydraulic conductivity.

\section{Experimental results and analysis}

\subsection{Rainfall}

The average rainfall amount per year was $1262(S D=230) \mathrm{mm}$, varying from $834 \mathrm{~mm}$ in 2009 to $1634 \mathrm{~mm}$ in 2016 (Fig. 4). In average, $83 \%$ of the rainfall volume occurred during the measurement period, from May to October. The rainfall events ranged from $2 \mathrm{~mm}$ to $182 \mathrm{~mm}$ with an average of $37(S D=27) \mathrm{mm}$. The maximum mean rainfall 


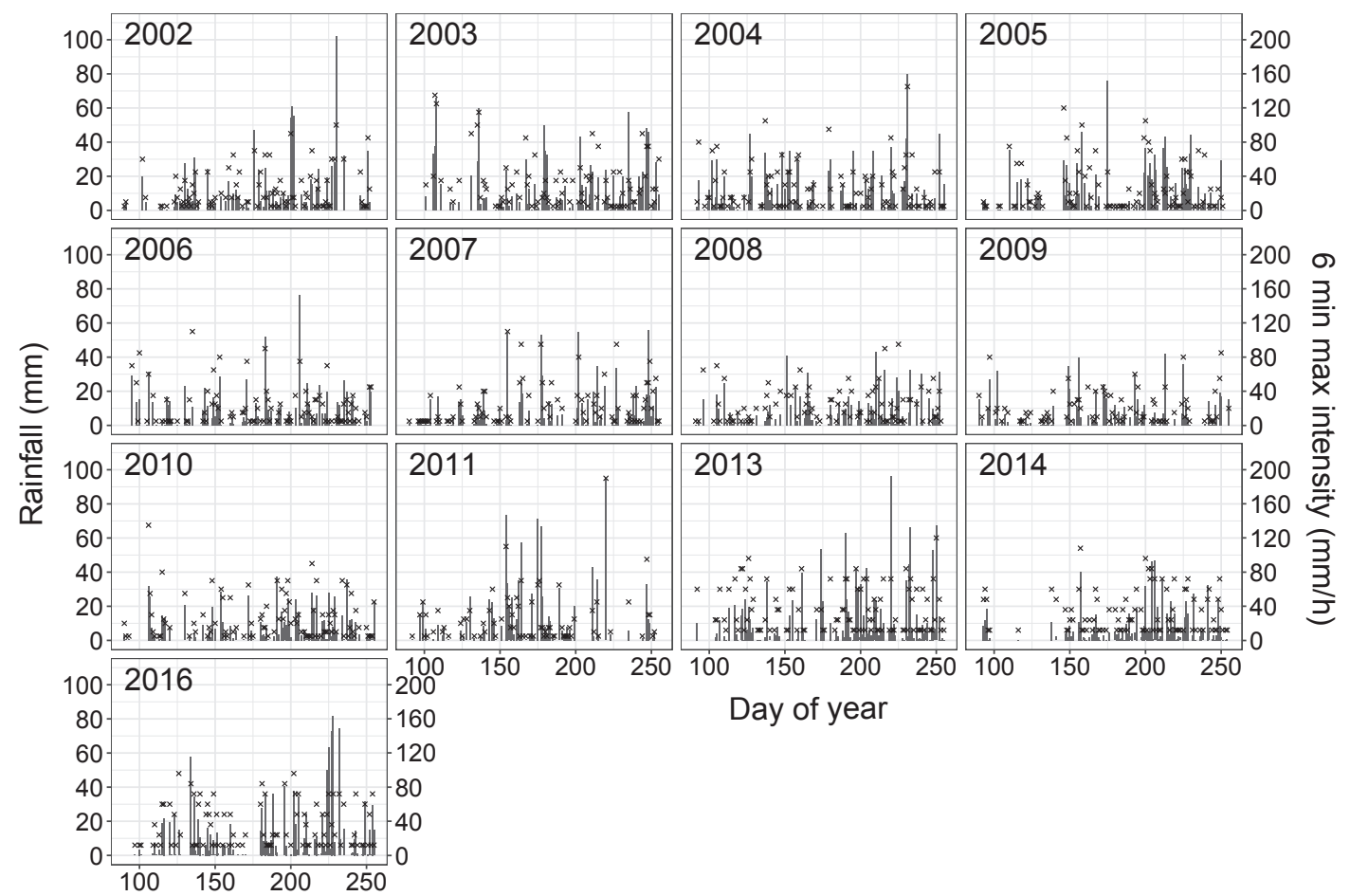

Fig. 5. Daily rainfall (vertical bars) and six-minutes maximum rainfall intensity during each rainfall event (crosses) for the period 2002-2016.

intensity of an event (rainfall amount divided by the event duration) was $52 \mathrm{~mm} \mathrm{~h}^{-1}$ and the maximum intensity on a $6 \mathrm{~min}$ interval was $190 \mathrm{~mm} \mathrm{~h}^{-1}$. Fig. 5 displays the daily rainfall and the six minutes maximum intensity during each rainfall event for the period 2002-2016. As shown in this figure, a wide variation of rainfall patterns was captured, from short and intense storms to long and gentle rains. The period between two measurements sometimes encompassed multiple days.

The measured kinetic energy content dependency on rainfall intensity (Fig. 6) was in good agreement with the exponential parametrization proposed by Kinnell (1981) and Van Dijk et al. (2002a) (Eq.

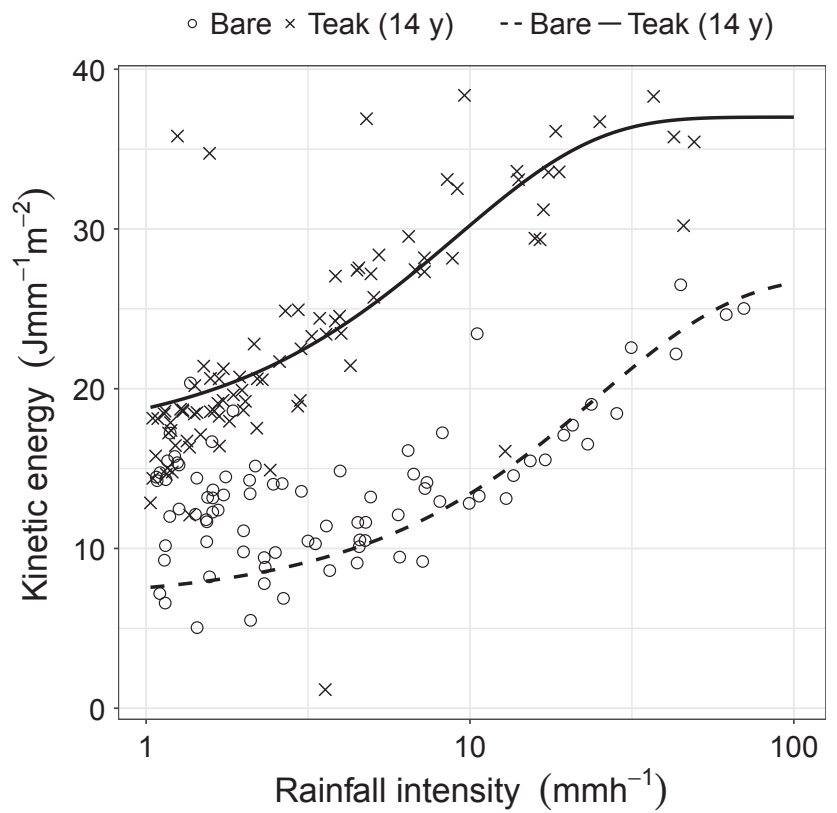

Fig. 6. Kinetic energy of the rain on bare soil in the open and under 14 years old teak tree, experimental (symbols) and fitted model (lines).
(6)). With \pm denoting the standard error, the estimated coefficients were $e_{k \max }=28.4 \pm 4.3 \quad \mathrm{~J} \quad \mathrm{~mm}^{-1} \quad \mathrm{~m}^{-2}, \quad a=0.66 \pm 0.04 \quad$ and $b=0.02 \pm 0.01 \mathrm{~h} \mathrm{~mm}^{-1}$ for bare soil in the open and $e_{\text {kmax }}=33.5 \pm 1.6$ $\mathrm{J} \mathrm{mm}^{-1} \mathrm{~m}^{-2}, a=0.70 \pm 0.18$ and $b=0.23 \pm 0.09 \mathrm{~h} \mathrm{~mm}^{-1}$ for 14 years old teak trees. The troughfall kinetic energy (TKE) under teak trees was consistently higher, at least twice as high, than rainfall kinetic energy on bare soils in the open, regardless of the intensity between $1 \mathrm{~mm} \mathrm{~h}^{-1}$ and $70 \mathrm{~mm} \mathrm{~h}^{-1}$. This is commonly explained by: (i) the large leaves of old teak trees (typically $30-60 \mathrm{~cm}$ in length) which concentrate droplets in their midvein and produce large droplets, and (ii) the effective falling height of a few meters (Ribolzi et al., 2017). This canopy effect has been observed and discussed for various tree species (Wiersum, 1985; Brandt, 1988; Hall and Calder, 1993; Geißler et al., 2012).

The TKE is expected to be highly dependent on the land use (Hall and Calder, 1993; Goebes et al., 2015). Compared to that of bare soil in the open, the TKE of a given land use may be higher or lower. Measurements of TKE under various trees and crops have been performed recently in a catchment close to Houay Pano (Lacombe et al., 2018). The authors of this study showed that TKE under broom grass is half of that in the open, whereas under vernicia or rubber trees, it is double. Different authors propose parametrizations of the TKE under the canopy of a tree or a crop. As an example, the model developed by Brandt (1988) and integrated in the European Soil Erosion Model EUROSEM (Morgan et al., 1998), proposes a parametrization which depends on the effective height of the plant canopy only. Given the great diversity of land uses and land use ages studied here, and for the sake of comparability, we consistently used the bare soil parametrisation of kinetic energy for all covers, teak trees included. However, it must be stressed that, as the soil loss is the product of the rainfall kinetic energy with soil detachability (Eq. (2)), an over-estimation of the kinetic energy content leads to underestimate soil detachability, and vice versa.

\subsection{Runoff, soil loss and surface features}

Annual means of runoff, soil loss and surface features were computed for each plot and each land use. The experimental results at the yearly scale are summarized in Table 2 . For each land use, the values 


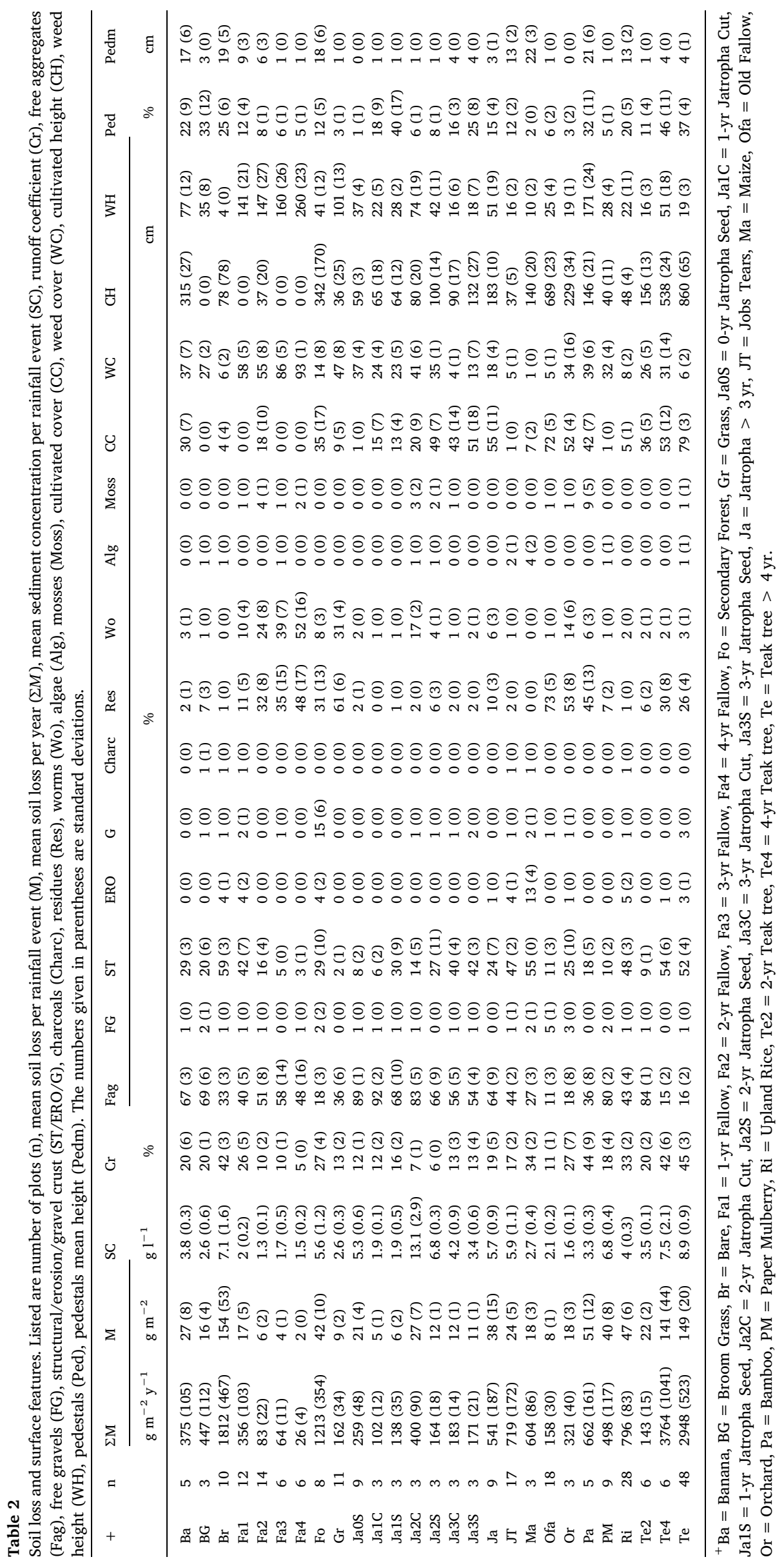



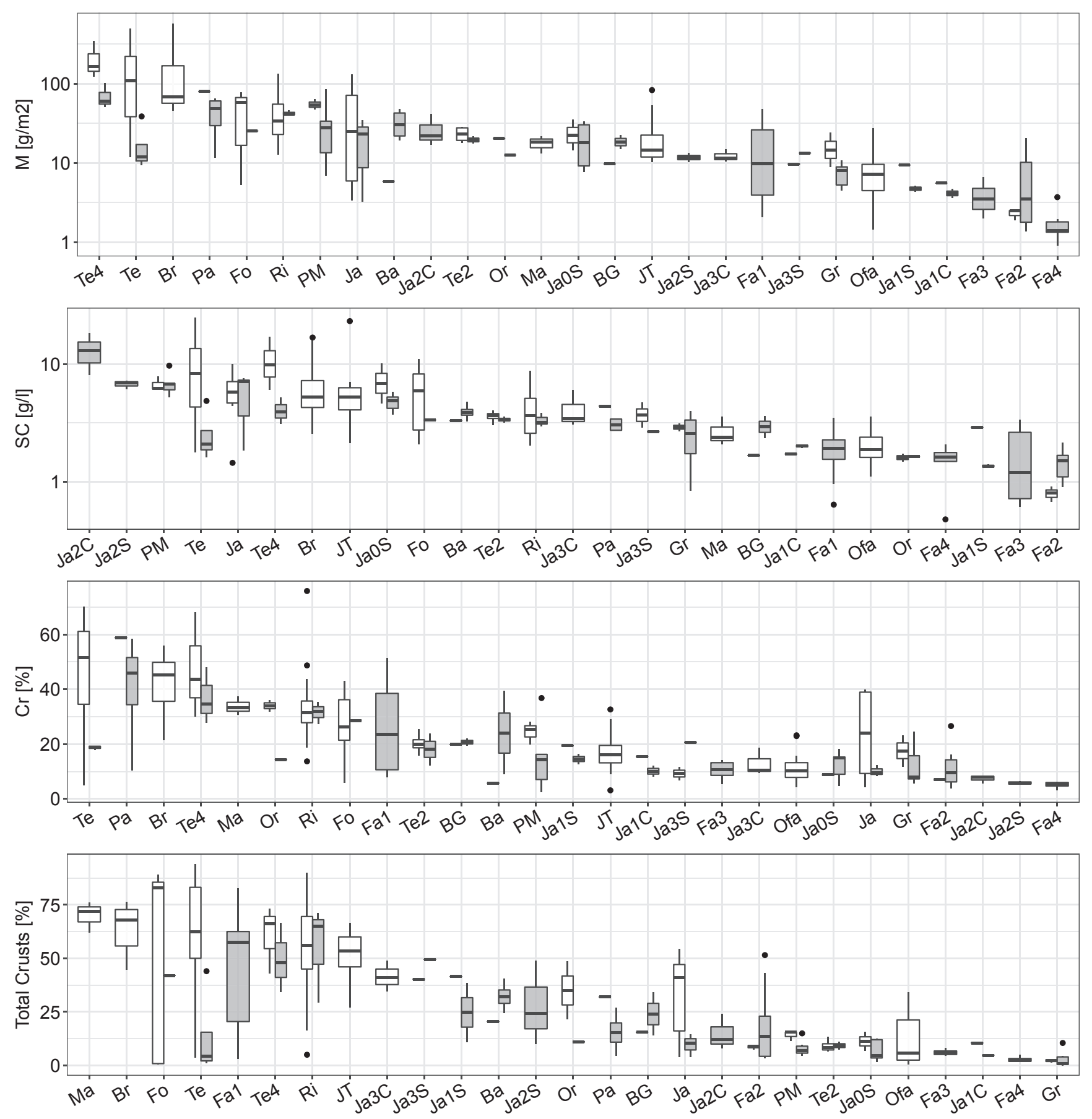

Fig. 7. Boxplots by land use of mean soil loss per rainfall event ( $M$, logarithmic scale), mean sediment concentration ( $S C$, logarithmic scale), runoff coefficient ( $C r$ ), and total crust cover, with a $20 \%$ threshold of weed cover. Ba = Banana, BG $=$ Broom Grass, Br $=$ Bare, Fa1 $=1$-yr Fallow, Fa2 = 2-yr Fallow, Fa3 $=3$-yr Fallow, Fa4 = 4-yr Fallow, Fo $=$ Secondary Forest, Gr $=$ Grass, Ja0S $=0$-yr Jatropha Seed, Ja1C $=1$-yr Jatropha Cut, Ja1S $=1$-yr Jatropha Seed, Ja2C $=2$-yr Jatropha Cut, Ja2S = 2-yr Jatropha Seed, Ja3C = 3-yr Jatropha Cut, Ja3S = 3-yr Jatropha Seed, Ja = Jatropha $>3$ yr, JT $=$ Jobs Tears, Ma $=$ Maize, Ofa $=$ Old Fallow, Or $=$ Orchard, $\mathrm{Pa}=$ Bamboo, $\mathrm{PM}=$ Paper Mulberry, $\mathrm{Ri}=$ Upland Rice, $\mathrm{Te} 2=2$-yr Teak tree, $\mathrm{Te} 4=4$-yr Teak tree, $\mathrm{Te}=\mathrm{Teak}$ tree $>4 \mathrm{yr}$.

given in this table are the means over the number $n$ of replica plots and means per rainfall event. The annual runoff coefficient and soil loss ranged respectively from $0.05(S D=0)$ and $26(S D=4) \mathrm{g} \mathrm{m}^{-2} \mathrm{yr}^{-1}$ for the 4 years old fallow to $0.45(S D=0.03)$ and $3764(S D=1041) \mathrm{g} \mathrm{m}^{-2}$ $\mathrm{yr}^{-1}$ for the 14 years old teak trees. While standard deviations were consistently high for the soil loss and low to intermediate for the runoff coefficient, they were relatively low for the surface features percentage. Table 2 shows that structural crusts are predominant for all the land uses, except the secondary forest and maize where percentages of gravel crusts and erosion crusts are comparable to that of structural crusts.

These results are also represented as boxplots in Fig. 7. A distinction was made for plots with more than $20 \%$ of weed cover. This threshold value allows to divide each land use into two groups of nearly equal weight. The presence of more than $20 \%$ of weeds on the surface visibly reduced soil losses, runoff coefficient and surface crusting (eg. teak trees, established jatropha and grass). These results are consistent with 
those published previously on runoff production during the period 2003-2009 (Patin et al., 2012). The plots of this period are indeed included in the set of plots analyzed in this work. For a given land use, we showed that the space and time variability of infiltrability, from one plot to another and a rainfall event to another, may be described by a log-normal distribution (see Hawkins and Cundy, 1987 for the definition of the infiltrability). This previous analysis of runoff production led to classify infiltrability values into three groups of land use. The lowest infiltrabilities were observed for teak tree and bare soil in the open, median $=10(G S D=3) \mathrm{mm} \mathrm{h}^{-1}$ and the highest for fallow and jatropha, median up to $105(G S D=2.8) \mathrm{mm} \mathrm{h}^{-1}$ (see Section 2.5 for the definition of the median value and the geometric standard deviation $G S D$ ). The infiltrability was found to be highly correlated with the total crust percentage. It is known that fallow develop an important biological activity in its rooted layer, leading to high layer porosity and infiltrability. Moreover, its high leaf area index reduces the throughfall kinetic energy. This leads to high infiltration rates, low crust percentage and consequently low soil detachment rates. At the opposite, teak trees, especially old teak trees which have an important canopy, produce energetic droplets which crush and clog the soil leading to soil crusting. This process lowers the infiltration and enhances splash erosion.

A correlation analysis was conducted on the scaled and normalised soil loss, the runoff coefficient and the surface features (Table 3). Prior to the analysis the data were transformed, i.e. scaled, to help them meet the distributional and variance assumptions required for linear models (Section 2.5). Surface features in percents were normalized using the arcsinus of the square root. This is the classical transformation for percentages, especially when the percentages are close to one or zero. Lengths, cultivated height and weed height, were normalized with the square root function which is applicable for mildly skewed distributions. Sediment masses and concentrations were scaled with the logarithm transformation. Annual soil loss was well correlated $(p<0.001)$ with all variables except the slope and the algae percentage, where $p$ is the Pearson significance level. Its highest correlations were obtained with the runoff coefficient $(r=0.83)$ and the total crust percentage ( $r=0.74$ ), where $r$ is the Pearson correlation coefficient. As structural crusts are predominant for almost all the land uses, the three types of crusts were not discriminated and the total crust percentage was considered (Table 2). The best negative correlations, which reflect a decrease of soil loss for an increase of a soil surface feature, were obtained for weed cover $(r=-0.53)$ and worms casts $(r=-0.49)$. Among all the negative correlations, we selected the weed cover and residues percentages as attenuation cover factors to be included in the soil loss equation (Eq. (4)). While these two features were found to be lowly correlated $(r=0.18, p<0.01)$, they exhibited high correlations with all the other features. This choice allowed to avoid collinearity effects in the regression analysis conducted on the model. Patin et al. (2012) showed in their analysis and modelling of runoff production on Houay Pano plots that infiltrability is decreasing with increasing crust percentage. Therefore, the increase of wash erosion with increasing crusts can be a consequence of less residues and weed cover, and more soil exposed to the rainfall.

As mentioned above, surface features have a low standard deviation when aggregated by land use (Table 2). This land use effect means that each land use produces a unique combination of surface features influenced by the canopy and its effects on the throughfall kinetic energy, leading to surface crusting, as well as an ability to develop a major layer of protection of the soil by weeds or residues. Because of this natural land use signature, the effect of surface features inside a given land use cannot be discriminated.

The control of erosion by the wide range of measured surface features was mostly consistent with Descroix et al. (2001), with the notable exception of the cultivated cover and plant height which are positively correlated with annual soil losses. The presence of teak trees, with high trunks and large leaves, associated with the highest soil losses, can explain the low but positive correlation observed. From a

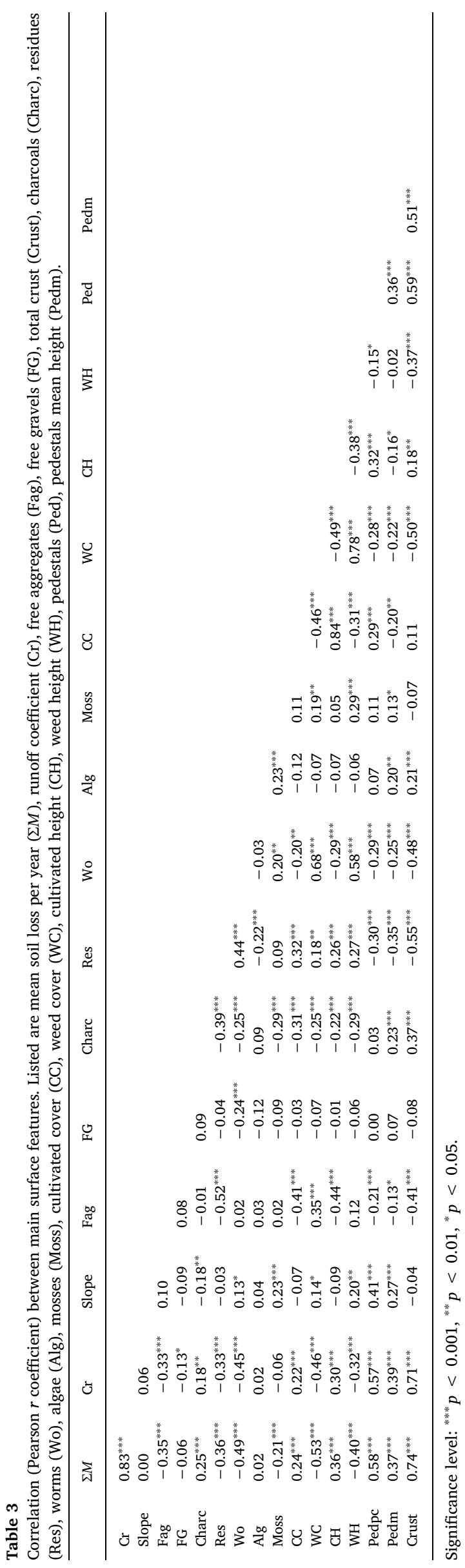


general point of view, it is acknowledged, particularly in tropical countries, that the litter layer help to prevent soil erosion (Wiersum, 1985; Ciesiolka et al., 1995; Zhou et al., 2002).

\subsection{Slope}

Since slope variations are unequally distributed over the land uses, with a variable number of plots from each land use, subtle effects of slope such as those described by Patin et al. (2012) on runoff production during the period 2003-2009 (decrease of infiltration until a threshold around $20 \%$, then increase with a land use dependency) were not depicted. Correlation between slope and interrill erosion rate has been observed by different authors on bare soils, under natural or simulated rainfall (Ribolzi et al., 2011; Zhang and Wang, 2017). Depending on the runoff and splash erosion processes involved, the correlation may be positive or negative. In Houay Pano catchment, a positive correlation has been observed and explained by a mechanical argument: a decrease in the local soil slope enhances the transfer of the raindrop kinetic energy to soil particles and, therefore, promotes particle crushing. As a consequence, a soil with a low slope produce more sediments than a soil with a high one (Ribolzi et al., 2011). When a landcover is present the overall erosion and transport process becomes much more complex and no clear correlations have been reported in the literature at the plot scale. For these reasons, all the plots with different slopes for a given land use were pooled together in the analysis.

\section{Annual soil loss model and soil detachability}

\subsection{Annual soil loss model}

The coefficients of the relationship linking the logarithm of the annual soil loss to the different rainfall, runoff and soil variables discussed in the previous section (Eq. (5)) were determined using a linear regression. From the correlation analysis we selected the factors which protect the soil from erosion, weed cover and residues percentages (Table 3). These two factors are negatively correlated with the mean soil loss and the least correlated between them. The crust percentage is not a protecting factor and, due to its high correlation with other surface features, its effect is reflected through them.

A significant linear regression was found $(F(3,250)=248.8, p<0.00)$, with an $R^{2}$ of $0.75 \quad$ : $\log (\Sigma M)=-1.93+1.09 \log \left(\Sigma E C_{r}\right)-1.00 W C-0.65$ Res, where $\Sigma M$ is the annual soil loss, $E$ the rainfall kinetic energy, $C_{r}$ the runoff coefficient and $\Sigma E C_{r}$ the sum on all the events of the year. All variables of the regression are significant $(p<0.001)$. Observed and modelled annual detachments compared on Fig. 8 are in good agreement. For the sake of visibility the soil losses plotted on this figure are identified by the vegetation age and not the type of land use. We see that the age, which could be correlated to the leaf area index, does not bring any information in this comparison. A plot by land use does not reveal much. The coefficient of $\Sigma E C_{r}$ is almost equal to one, as expected from Eq. (5). For further use, this coefficient was forced to be one and values of the decay characteristic parameters $\gamma_{W C}=1.12 \pm 0.17$ and $\gamma_{\text {Res }}=0.70 \pm 0.16$ (Eq. (4)) were obtained with a non linear fit, exactly as for Eq. (5). With these values, for a cover of $60 \%$ of weeds or residues the attenuation factors are $50 \%$ and $35 \%$ respectively. In the application of their model Van Dijk and Bruijnzeel (2004b) used a threshold on rainfall intensities to estimate kinetic energy. In our case, this did not improve the quality of the regression. The values of the $\gamma$ factors are comparable to those inferred by Van Dijk and Bruijnzeel (2004b) for various surface covers on bench terraces in West Java, except for mulch found to be higher by these authors, up to 3 and 4 .

A simple annual soil loss model describing the soil loss as a function of the runoff coefficient was also obtained with the relationship $\log (\Sigma M)=8.37+1.50 \log \left(\Sigma C_{r}\right)$. This approximation is statistically significant $\left(F(1,252)=550.8, p<0.00, R^{2}=0.68\right)$ but, as the rainfall

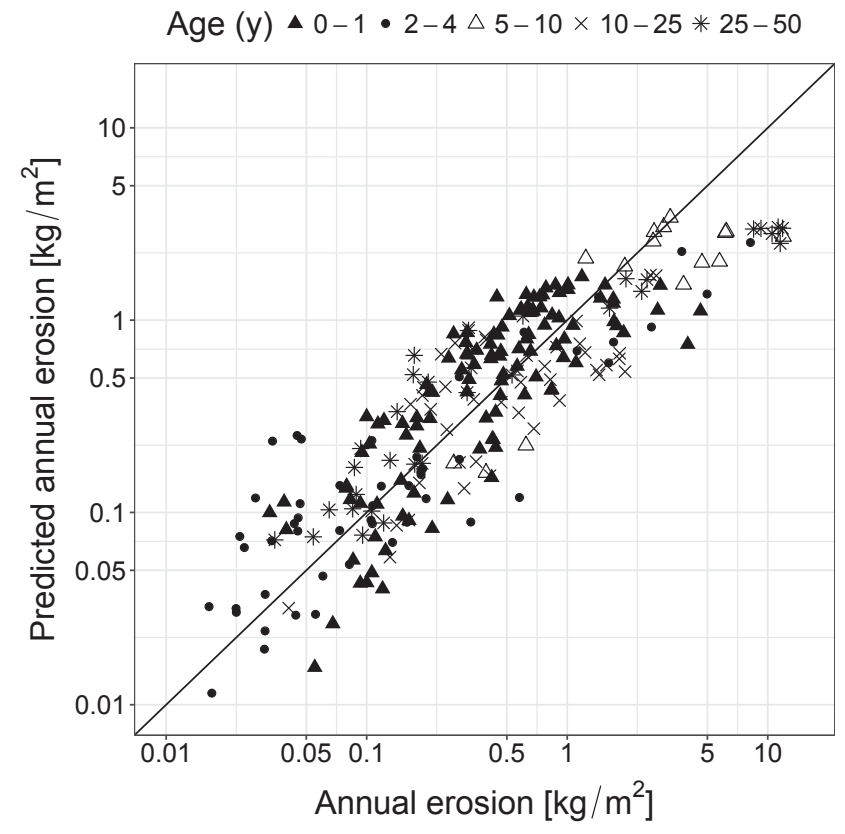

Fig. 8. Observed and modelled annual soil loss: $\log (\Sigma M)=-1.93+1.09 \log \left(\Sigma E C_{r}\right)-1.00 W C-0.65$ Res, where $\Sigma$ is the sum on all the events of the year, $E$ and $C_{r}$ respectively the rainfall kinetic energy and the runoff coefficient of the event, $W C$ and Res the weed cover and residues percentages respectively. Symbols refer to age classes across vegetation types.

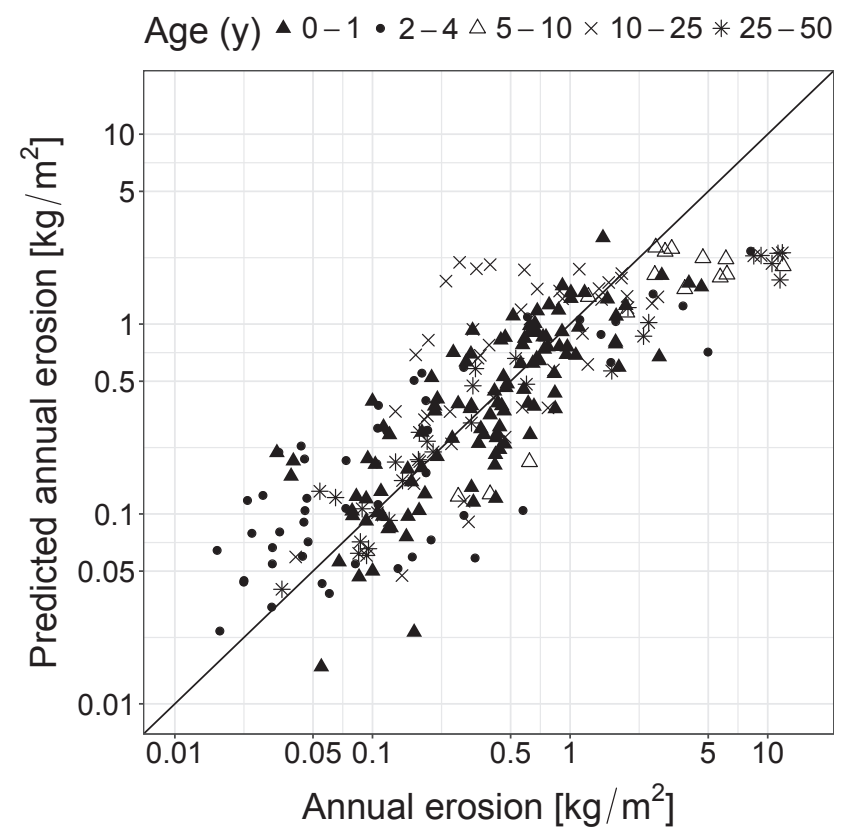

Fig. 9. Observed and modelled annual soil loss: $\log (\Sigma M)=8.37+1.50 \log \left(\Sigma C_{r}\right)$, where $\Sigma$ is the sum on all the events of the year and $C_{r}$ the runoff coefficient of the event. Symbols refer to age classes across vegetation types.

kinetic energy is absent of this simple model, it cannot be interpreted from a physical point of view. Nevertheless, it shows that the runoff coefficient is the main statistical driving variable of the soil loss process. Observed and modelled annual soil losses are compared on Fig. 9. Both models are independent of the land use and use few experimental inputs that are easy to collect. They provide a reliable framework to describe the washed fraction at the micro-plot scale.

These two soil loss regressions can be compared to the regression proposed recently by Ribolzi et al. (2017) to estimate the Houay Pano 


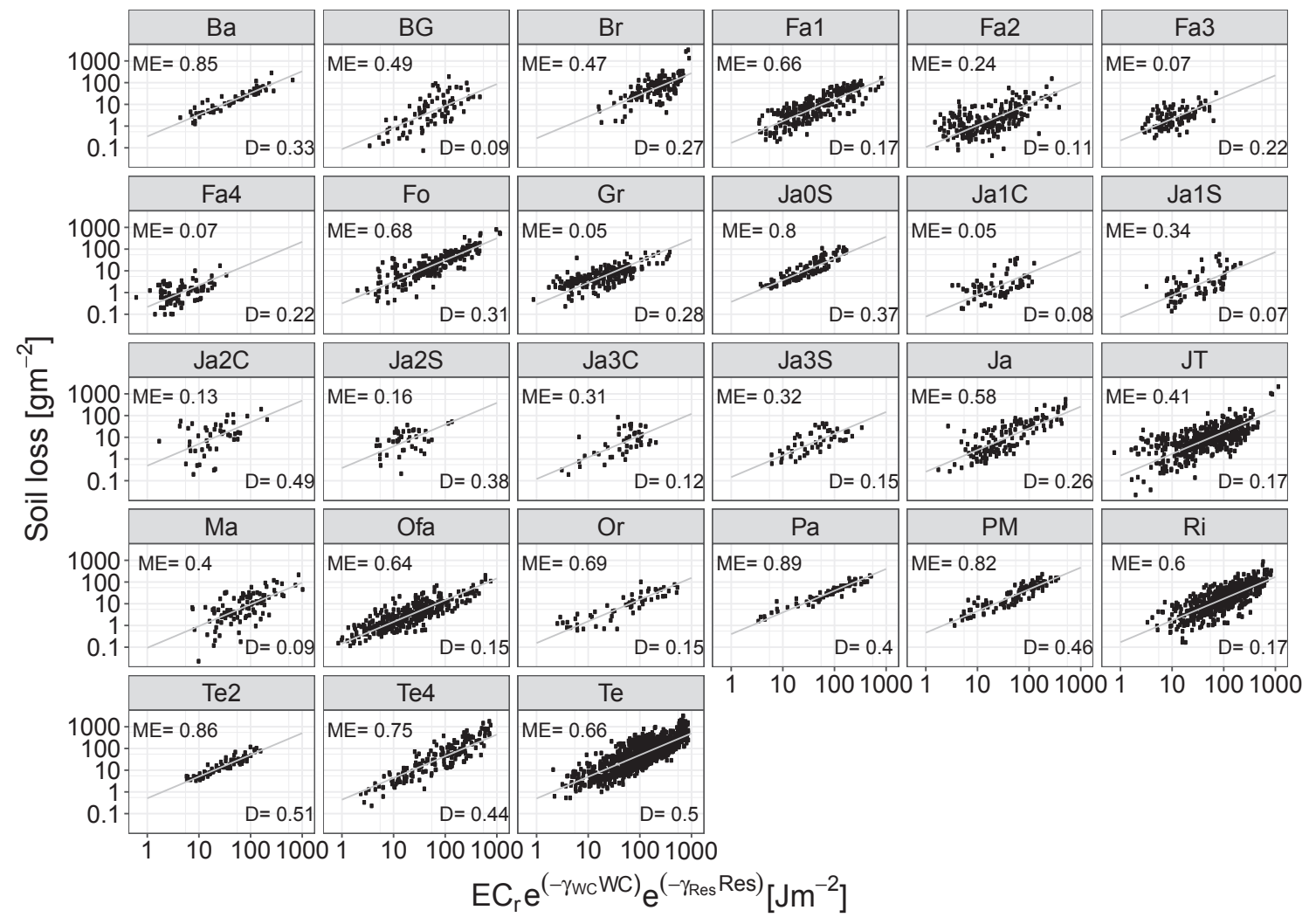

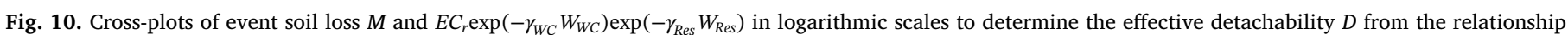

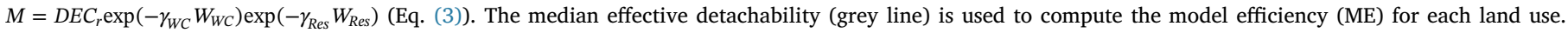

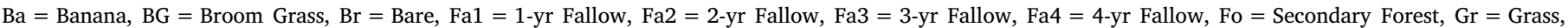

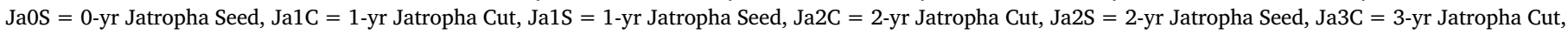

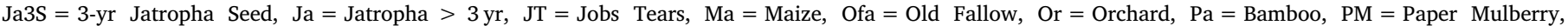
$\mathrm{Ri}=$ Upland Rice, Te2 $=2$-yr Teak tree, Te4 $=4$-yr Teak tree, Te $=$ Teak tree $>4 \mathrm{yr}$.

mean annual sediment yield over the period 2002-2014. At the catchment scale, and with the authors' notations, the sediment yield regression is $S Y=0.156 F_{O L F}+0.024$ Rain $_{F}-966.0\left(R^{2}=82.8\right)$, where $S Y$ $\left(\mathrm{Mg} \mathrm{km}^{-2}\right)$ is the sediment yield, $F_{O L F}(\%)$ the annual median of overland flow contribution to total depth of each flood event, and $\operatorname{Rain}_{F}$ $(\mathrm{mm})$ the annual flood-triggering rainfall depth. The rainfall events considered in this regression are those which produced stormflow only (32\% of the events). The overland flow contribution was estimated using tracer-based hydrograph separation and the contributions of surface and sub-surface soil sources to stream sediment exports were discriminated by measuring the activity of Caesium-137. Sediment load is the main export route for soil particles and its contribution to the sediment yield is on average lying between $70 \%$ and $80 \%$. The annual sediment yield exhibited large inter-annual fluctuations between $10 \mathrm{Mg}$ $\mathrm{km}^{-2}$ and $1260 \mathrm{Mg} \mathrm{km}^{-2}$, with an inter-median of $98 \mathrm{Mg} \mathrm{km}^{-2}$ for the period 2002-2009 and $609 \mathrm{Mg} \mathrm{km}^{-2}$ for the period 2010-2014. The difference between the two periods comes from an important increase of the teak tree plantation area between the first and the second period. These values are smaller by a factor two or tree, in average, than those measured at the plot scale (Table 2). This scale effect is frequently observed and explained as the result of a multi-scale complex process of production, transport, deposition and remobilization of sediment particles (Sidle et al., 2017). At Houay Pano catchment, rills are known to play an active role in the sediment export, but the sediment flux into the stream is greatly buffered by the riparian vegetation (Vigiak et al., 2008). It is interesting to note that the erosion rates measured at the two scales, plot and catchment, are in a pretty agreement with the results of the meta-analysis of soil erosion rates across the world performed by García-Ruiz et al. (2015). These authors show in the form of a scatter plot diagram of frequencies, the relationship between the erosion rate and the size of the study area. The studied areas are mostly located in North America and Europe, and the Asian sites mainly in China. The polynomial regression associated to the scatter plot gives approximatively $450 \mathrm{Mg} \mathrm{km}^{-2}$ for $1 \mathrm{~m}^{2}$, value to be compared to annual soil loss values of Table 2, and $200 \mathrm{Mg} \mathrm{km}^{-2}$ for 62 ha, the Houay Pano catchment area. Erosion rates under teak trees or sediment yields measured during the expansion of the teak tree plantation fall quite above the regression, i.e. far outside the $95 \%$ confidence interval.

The explanatory variables of the sediment yield, $S Y$, and mass soil loss, $\Sigma M$, regressions are different. The flood-triggering rainfall depth $\operatorname{Rain}_{F}$ gives probably a measure of the rainfall kinetic energy averaged over the catchment area and over a given year, but the annual median of overland flow contribution $F_{O L F}$ cannot be easily connected to a runoff coefficient. It is worth to note that in the spatial upscaling of the soil loss regression, from the plot scale to the catchment scale, the time scale of the explanatory variables is changing. Spatial upscaling from the plot scale to the catchment scale goes with temporal upscaling from the event scale to the annual scale.

\subsection{Effective soil detachability}

With the plot's surface observations available yearly, if we assume as a first approximation that the decay characteristic parameters of the residues and weed cover, $\gamma_{\text {Res }}$ and $\gamma_{W C}$ respectively, do not depend on the land use, then the mass soil loss as given by Eq. (3) can be applied at the event scale to determine the effective soil detachability $D$. This was done after correction with the exponential attenuation factors obtained from the mean annual soil loss equation (Eq. (5)). Fig. 10 displays as a 


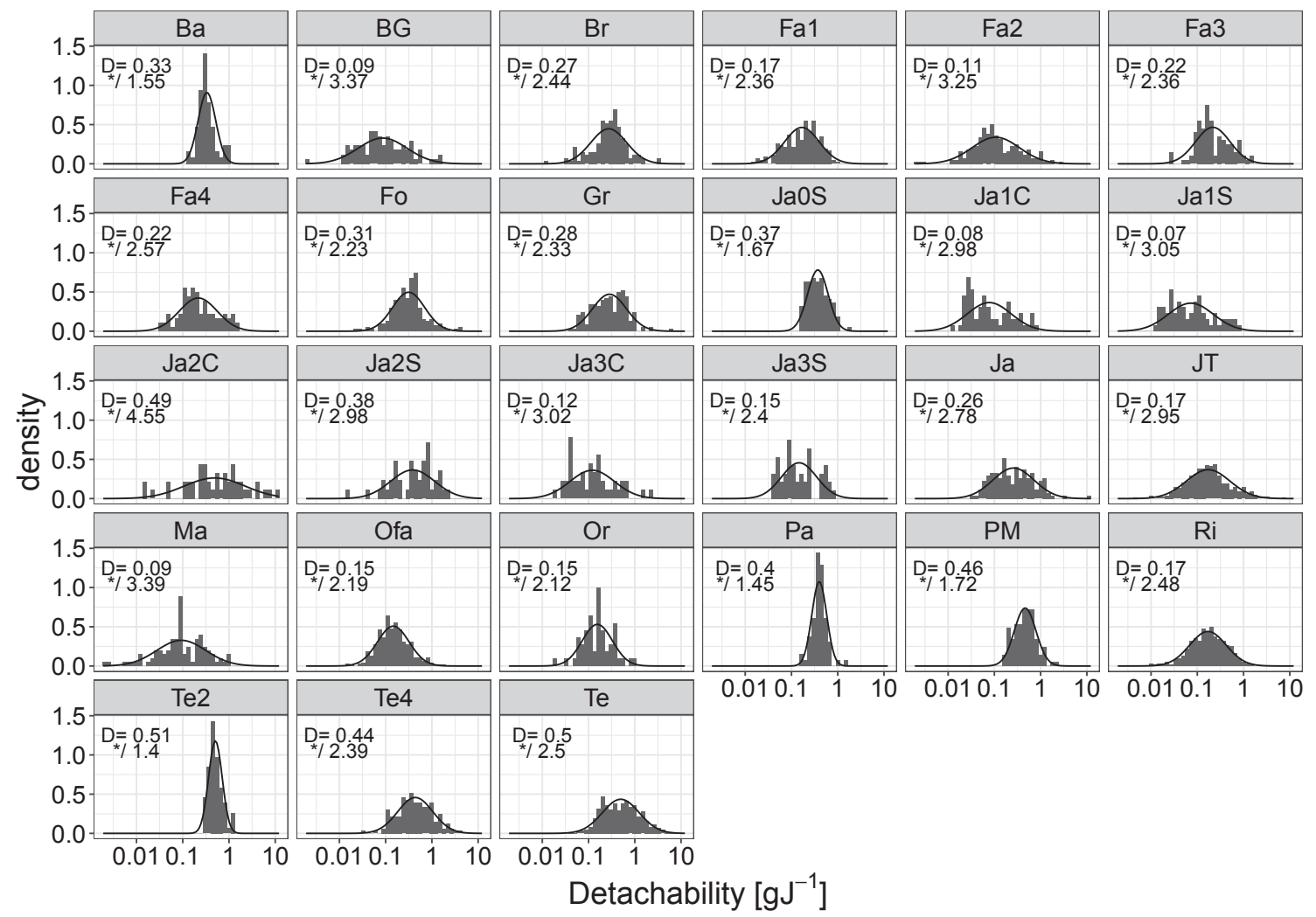

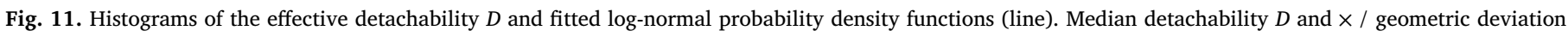

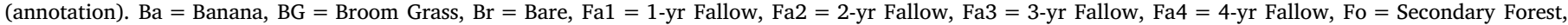

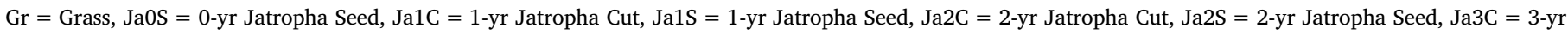

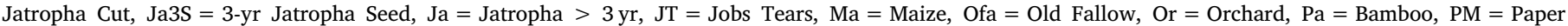
Mulberry, $\mathrm{Ri}=$ Upland Rice, $\mathrm{Te} 2=2$-yr Teak tree, Te4 $=4$-yr Teak tree, $\mathrm{Te}=$ Teak tree $>4 \mathrm{yr}$.

scatter plot diagram the event soil loss $M$ as a function of the expression $E C_{r} \exp \left(-\gamma_{R e s} W_{R e s}\right) \exp \left(-\gamma_{W C} W_{W C}\right)$ for each land use (Eq. (3)). The slope of the line passing through the origin and one point of the diagram is the effective detachability for the considered rainfall event and land use. The resulting effective detachability distribution was modelled as a log-normal distribution for each land use (Fig. 11). Such a distribution is classical to describe the variability of soil and rock intrinsic physical and mechanical properties and it was used previously to describe the spatial and temporal variability of plot infiltrability (Patin et al., 2012). With GSD standing for the standard geometric deviation (Section 2.5), the median effective detachability ranged from $0.07(G S D=3.05) \mathrm{g} \mathrm{J}^{-1}$, for 1 year old jatropha from seeds, to $0.51(G S D=1.40) \mathrm{g} \mathrm{J}^{-1}$ for 2 years old teak trees.

The effective detachability was constant along the year for some land uses such as Bamboo (Fig. 12). It showed seasonal variations (Fig. 12) for a number of year-land use combinations. As such, broom grass in 2016 presents a highly skewed distribution associated with a decreasing detachability along the year. It must be remembered that, though throughfall kinetic energy is highly dependent on the land use, the kinetic energy curve measured on the plot in the open has been used for all the land uses. As discussed in Section 3.1, this assumption may lead to an over- or underestimation of detachability. This explains probably the difference of nearly two orders of magnitude between the median effective detachabilities of 1 year old jathropha (0.07) and 2 years old teak tree (0.51). Measurements of throughfall kinetic energy performed recently in a catchment close to Houay Pano showed that broom grass intercept a large amount of rainfall and reduce rainfall kinetic energy compared to that in the open (Lacombe et al., 2018). This is due to a short, dense and umbrella-shaped canopy. Fig. 12 shows successive periods of high daily rainfalls during the rainy season of the summer 2016, between 40 and $80 \mathrm{~mm}^{-1}$. Troughfall kinetic energy is probably overestimated during these periods, and detachability consequently underestimated. Compared to 2016, the daily rainfall distribution of 2006 is more "flat", except the two peaks of 40 and 80 $\mathrm{mm}^{-1}$, with maxima of daily rainfall of the order of $20 \mathrm{~mm}^{-1}$ (see also the monthly rainfall distributions in Fig. 4). Crop growth is also a factor to be considered in the analysis of detachability variations. Broom grass is planted at the end of the dry season and its canopy develops rapidly during the rainy months. This growth impacts certainly the throughfall kinetic energy.

Shallow flow transport of the washed sediments is approximated by $j$, the fraction of the sediments carried to the outlet, itself incorporated in $D$, the effective detachability, where $D=j d$ with $d$ the detachability (Section 2.3). Being a multiplicative factor in the mass soil loss equation (Eq. (3)), the fraction $j$ cannot be discriminated from $D$ in the model calibration. The unknown variations of $j$ are less impacting at the yearly scale, where previously unwashed sediment can be remobilized from one event to another one. Putting aside the assumption of a single throughfall kinetic energy for all land uses, detachability can be assumed constant if the soil surface is not evolving, because of crusting or other process. Thus, variations of $D$ as observed on Fig. 12 and the corresponding distribution skewness (Fig. 11) can be also explained as variations of $j$ or inter-annual variations of weed or residues covering the soil. They may be also due to abnormally erosive human actions such as plowing.

Van Dijk and Bruijnzeel (2004b) obtained after calibration of their splash and wash model on each instrumented terrace a mean detachability $d$ equal to $11.7 \mathrm{~g} \mathrm{~J}^{-1}$ and a mean $j$ value to $4 \%$. This gives a mean effective detachability value, $D=0.46$, which is comparable to the median values given in Fig. 11 for each land use. These authors also pointed out the important temporal variability of the detachability, linked essentially to crop growth. 

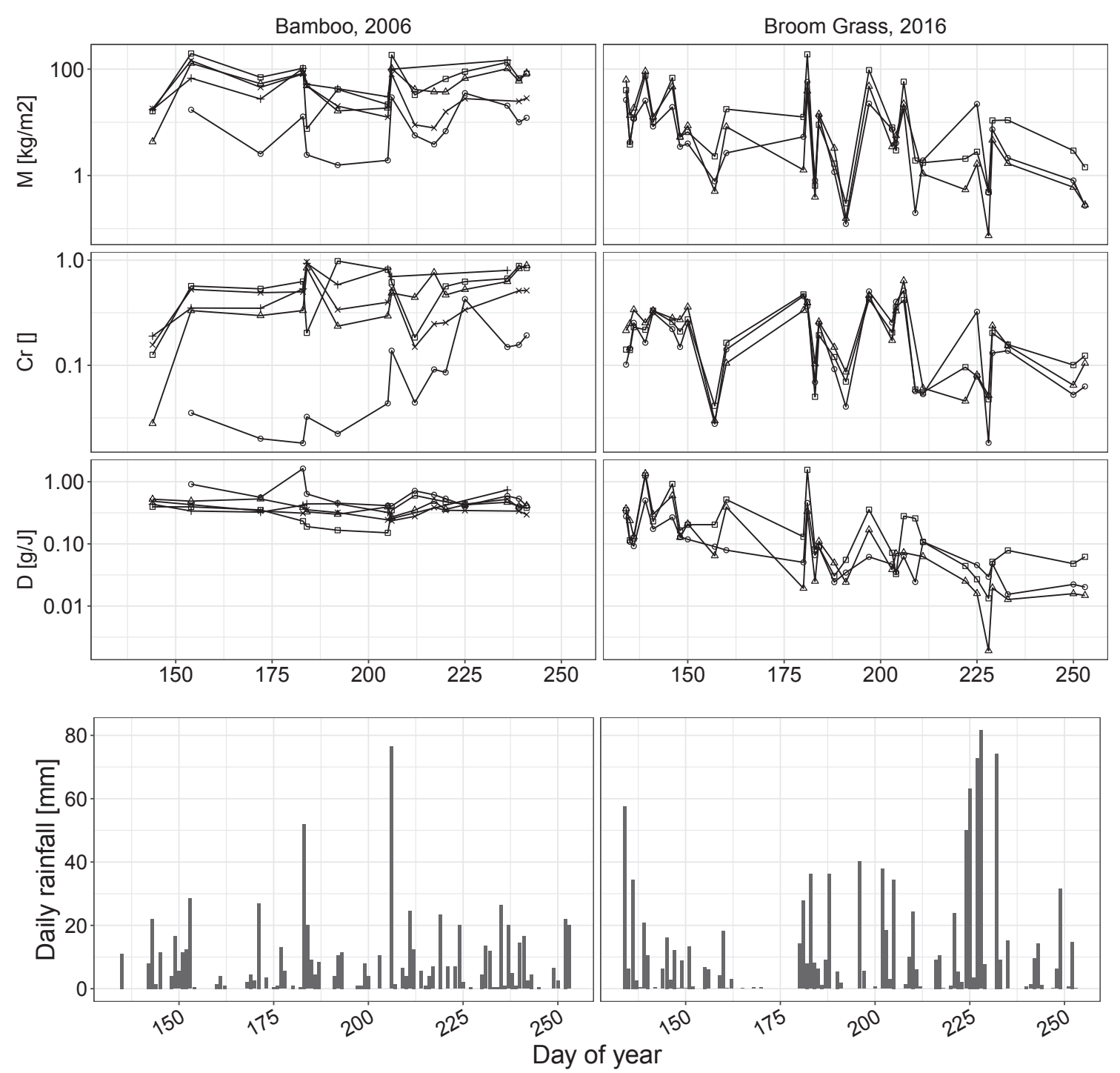

Fig. 12. Time series of soil losses (M), runoff coefficient (Cr), detachability (D) and daily rainfall. Symbols refer to individual plots $(B G=B r o o m ~ G r a s s, ~ P=B a m b o o)$.

Model efficiency (Nash) was computed for each plot with a detachability calibrated from a set excluding the considered plot. The efficiency was negative for 54 plots and values ranged from 0 to 0.95 with a mean efficiency of 0.50 for the remaining 200 plots (Fig. 10). Sediment concentration was highly correlated with detachability $\left(D=0.06+0.07 S C, F(1,4794)=17160, p<0.00, R^{2}=0.78\right)$ and as such varied between plots and land uses.

\section{Conclusion and Perspectives}

This work reports the analysis and the modelling of 13-year measurements of $1 \mathrm{~m}^{2}$ plot erosion in a small agricultural montane catchment of Northern Laos. This long term study confirms what has been observed over short periods: old fallow promotes infiltration and reduces erosion and, in contrast, teak tree increases soil crusting, lowers the infiltration rate and enhances soil detachment. A statistical analysis allowed us to determine the correlations between the surface features and the soil loss for each land use. The weed cover and the residues appeared to be the principal and independent features having a protective effect. The splash and wash model proposed by Van Dijk and Bruijnzeel (2004b) was calibrated and applied to the whole survey period and for all the land uses. Modelling and experimental results for yearly soil losses were in good agreement. Moreover, the use of a simple regression model between soil loss and runoff coefficient appeared to be also pertinent. For a given land use, the time and spatial variabilities of the calibrated soil detachability were described with a log-normal distribution, allowing for a stochastic interpretation of the soil loss process. These results show that the splash model can be used to describe interill erosion at the catchment scale for any mosaic of planted crops. The analysis of the impact of surface features led us to suggest that the incorporation in the splash model of attenuation factors evolving with the rainfall event sequence in the year would be a plus. Moreover, the splash and wash model was implemented with the rainfall intensitykinetic energy relationship of a bare plot in the open for all the land uses, and whatever their stage of growth. Though the revision of this assumption is not a straightforward task in our case (27 land uses), the parametrizations of the throughfall kinetic energy proposed in the literature should help to improve it.

In summary, this work showed that: (i) at the micro-plot scale, the mass soil loss depends primarily on the runoff coefficient; (ii) weeds and residues, directly associated with lower soil losses and incorporated in the splash and wash model as attenuation factors, improve 
significantly the model; (iii) each land use has a unique signature in the erosion process given by the surface features percentages and a soil detachability distribution; (iv) the splash and wash model is a valuable tool to describe micro-plot erosion: it is physically based, parsimonious, and therefore easy to calibrate. From a land management point of view, these surface features could be considered as a remediation to high erosion situations such as those encountered in tropical montane catchments. Therefore, leaving understorey and a litter layer under teak trees and crops should help to protect significantly the soil surface from erosion, and removing the litter material and burning the understorey should be discouraged.

A previous analysis of runoff production on the experimental plots with the Soil Variable Infiltration (SVI) model developed by Yu et al. (1997) and used by Van Dijk and Bruijnzed (2004a) showed that for a given land use the maximum infiltration rate varies a lot from one rainfall event to another and one plot to another. This observation led us to model the infiltration and runoff production process for a given land use as varying with space and time, and propose a stochastic approach where the maximum infiltration rate is described by a lognormal probability density function (pdf) which characteristics depend on the land use (Patin et al., 2012). This stochastic assumption allowed to encompass: (i) the spatial variabilities of infiltration properties, due to soil physical and geometrical heterogeneities, and throughfall intensity for a given land use, and (ii) the conceptual approximations introduced by the heuristic SVI model which cannot describe all the complexity of the infiltration process at the field. The same stochastic approach may be adopted here in the local application of the splash and wash model of Van Dijk and Bruijnzeel (2004b). The physical variable of the erosion process equivalent to the maximum infiltration rate is the effective soil detachability. As for infiltration, the stochastic assumption allows to encompass for each land use: (i) the space and time variabilities of surface features percentages and fraction of transported sediments; (ii) the lack of knowledge of the rainfall kinetic energy curve; (iii) the conceptual approximations of the splash and wash model.

Therefore, one modelling perspective would be to compute for each land use and each rainfall event the pdf of the runoff coefficient and the subsequent pdf of the soil loss, and compare this pdf with the experimental results. This type of comparison would permit to assess from a probabilistic point of view the prediction capability of such a global runoff splash erosion model for the plot scale in field conditions.

\section{Acknowledgements}

This work has been funded by the French National Agency for Research (TecItEasy project, ANR-13-AGRO-0007). The authors acknowledge with gratitude the numerous BSc students of the Faculty of Agriculture of the National University of Laos who took part in the project. The authors would also like to thank the anonymous reviewers for their valuable comments and suggestions that greatly contributed to the improvement of the manuscript.

\section{References}

Brandt, J., 1988. The transformation of rainfall energy by a tropical rain forest canopy in relation to soil erosion. J. Biogeogr. 15 (1), 41-48.

Bruijnzeel, L.A., 2004. Hydrological functions of tropical forests: not seeing the soil for the trees? Agric. Ecosyst. Environ. 104 (1), 185-228.

Casenave, A., Valentin, C., 1992. A runoff capability classification system based on sur face features criteria in semi-arid areas of West Africa. J. Hydrol. 130 (1-4), 231-249.

Causse, J., Billen, G., Garnier, J., Henri-des Tureaux, T., Olasa, X., Thammahacksa, C., Latsachak, K.O., Soulileuth, B., Sengtaheuanghoung, O., Rochelle-Newall, E., et al., 2015. Field and modelling studies of Escherichia coli loads in tropical streams of montane agro-ecosystems. J. Hydro-Environ. Res. 9 (4), 496-507.

Chaplot, V., Khampaseuth, X., Valentin, C., Le Bissonnais, Y., 2007. Interrill erosion in the sloping lands of Northern Laos subjected to shifting cultivation. Earth Surf. Proc. Land. 32 (3), 415-428.

Chaplot, V., Le Bissonnais, Y., 2000. Field measurements of interrill erosion under different slopes and plot sizes. Earth Surf. Proc. Land. 25 (2), 145-153.
Chaplot, V., Poesen, J., 2012. Sediment, soil organic carbon and runoff delivery at various spatial scales. Catena 88 (1), 46-56.

Chaplot, V., Rumpel, C., Valentin, C., 2005. Water erosion impact on soil and carbon redistributions within the Mekong basin. Global Biogeochem. Cycles 19 (4), 20-32.

Ciesiolka, C., Coughlan, K., Rose, C., Escalante, M., Hashim, G.M., Paningbatan Jr, E., Sombatpanit, S., 1995. Methodology for a multi-country study of soil erosion management. Soil Technol. 8 (3), 179-192.

Descroix, L., Viramontes, D., Vauclin, M., Barrios, J.G., Esteves, M., 2001. Influence of soil surface features and vegetation on runoff and erosion in the Western Sierra Madre (Durango, Northwest Mexico). Catena 43 (2), 115-135.

Ducourtieux, O., Visonnavong, P., Rossard, J., 2006. Introducing cash crops in shifting cultivation regions-the experience with cardamom in Laos. Agrofor. Syst. 66 (1), 65-76.

Evrard, O., Laceby, J.P., Huon, S., Lefèvre, I., Sengtaheuanghoung, O., Ribolzi, O., 2016. Combining multiple fallout radionuclides $\left({ }^{137} \mathrm{Cs},{ }^{7} \mathrm{Be},{ }^{210} \mathrm{~Pb}\right)$ to investigate temporal sediment source dynamics in tropical, ephemeral riverine systems. J. Soils Sediments 16 (3), 1130-1144.

Fang, N., Wang, L., Shi, Z., 2017. Runoff and soil erosion of field plots in a subtropical mountainous region of China. J. Hydrol. 552, 387-395.

Furbish, D.J., Hamner, K.K., Schmeeckle, M., Borosund, M.N., Mudd, S.M., 2007. Rain splash of dry sand revealed by high-speed imaging and sticky paper splash targets. J. Geophys. Res.: Earth Surface 112 (F1).

García-Ruiz, J.M., Beguerfa, S., Nadal-Romero, E., González-Hidalgo, J.C., Lana-Renault, N., Sanjuán, Y., 2015. A meta-analysis of soil erosion rates across the world. Geomorphology 239, 160-173.

Geiler, C., Kühn, P., Böhnke, M., Bruelheide, H., Shi, X., Scholten, T., 2012. Splash erosion potential under tree canopies in subtropical SE China. Catena 91, 85-93.

Goebes, P., Bruelheide, H., Härdtle, W., Kröber, W., Kühn, P., Li, Y., Seitz, S., von Oheimb, G., Scholten, T., 2015. Species-specific effects on throughfall kinetic energy in subtropical forest plantations are related to leaf traits and tree architecture. PloS one 10 (6).

Hairsine, P., Rose, C., 1991. Rainfall detachment and deposition: sediment transport in the absence of flow-driven processes. Soil Sci. Soc. Am. J. 55 (2), 320-324.

Hall, R.L., Calder, I.R., 1993. Drop size modification by forest canopies: measurements using a disdrometer. J. Geophys. Res.: Atmos. 98 (D10), 18465-18470.

Hawkins, R., Cundy, T., 1987. Steady-state analysis of infiltration and overland flow for spatially-varied hillslopes. J. Am. Water Resour. Assoc. 23, 251-256.

Huon, S., De Rouw, A., Bonté, P., Robain, H., Valentin, C., Lefèvre, I., Girardin, C., Le Troquer, Y., Podwojewski, P., Sengtaheuanghoung, O., 2013. Long-term soil carbon loss and accumulation in a catchment following the conversion of forest to arable land in Northern Laos. Agric. Ecosyst. Environ. 169, 43-57.

Huon, S., Evrard, O., Gourdin, E., LefFrre, I., Bariac, T., Reyss, J.-L., des Tureaux, T.H., Sengtaheuanghoung, O., Ayrault, S., Ribolzi, O., 2017. Suspended sediment source and propagation during monsoon events across nested sub-catchments with contrasted land uses in Laos. J. Hydrol.: Regional Stud. 9, 69-84.

Kinnell, P., 1981. Rainfall intensity-kinetic energy relationships for soil loss prediction. Soil Sci. Soc. Am. J. 45 (1), 153-155.

Kinnell, P., 2005. Raindrop-impact-induced erosion processes and prediction: a review. Hydrolog. Processes 19 (14), 2815-2844.

Lacombe, G., Ribolzi, O., De Rouw, A., Pierret, A., Latsachak, K., Silvera, N., Pham Dinh, R., Orange, D., Janeau, J.-L., Soulileuth, B., et al., 2016. Contradictory hydrological impacts of afforestation in the humid tropics evidenced by long-term field monitoring and simulation modelling. Hydrol. Earth Syst. Sci. 20, 2691-2704.

Lacombe, G., Valentin, C., Sounyafong, P., de Rouw, A., Soulileuth, B., Silvera, N., Pierret, A., Sengtaheuanghoung, O., Ribolzi, O., 2018. Linking crop structure, throughfall, soil surface conditions, runoff and soil detachment: 10 land uses analyzed in Northern Laos. Sci. Total Environ. 616, 1330-1338.

Limpert, E., Stahel, W., Abbt, M., 2001. Log-normal distributions across the sciences: keys and clues. Bioscience 51 (5), 341-352.

Liu, J., Liu, W., Zhu, K., 2018. Throughfall kinetic energy and its spatial characteristics under rubber-based agroforestry systems. Catena 161, 113-121.

Morgan, R., Quinton, J., Smith, R., Govers, G., Poesen, J., Auerswald, K., Chisci, G., Torri, D., Styczen, M., 1998. The european soil erosion model (EUROSEM): a dynamic approach for predicting sediment transport from fields and small catchments. Earth Surf. Proc. Land. 23 (6), 527-544.

Nanko, K., Giambelluca, T., Sutherland, R., Mudd, R., Nullet, M., Ziegler, A., 2015. Erosion Potential under Miconia calvescens Stands on the Island of Hawaï. Land Degradation Devel. 26 (3), 218-226.

Nord, G., Esteves, M., 2005. PSEM2D: a physically based model of erosion processes at the plot scale. Water Resour. Res. 41 (8).

Patin, J., Mouche, E., Ribolzi, O., Chaplot, V., Sengtahevanghoung, O., Latsachak, K., Soulileuth, B., Valentin, C., 2012. Analysis of runoff production at the plot scale during a long-term survey of a small agricultural catchment in Lao PDR. J. Hydrol. 426, 79-92.

Planchon, O., Mouche, E., 2010. A physical model for the action of raindrop erosion on soil microtopography. Soil Sci. Soc. Am. J. 74 (4), 1092-1103.

Quinn, G.P., Keough, M.J., 2002. Experimental Design and Data Analysis for Biologists. Cambridge University Press.

Ribolzi, O., Cuny, J., Sengsoulichanh, P., Mousques, C., Soulileuth, B., Pierret, A., Huon, S., Sengtaheuanghoung, O., 2011. Land use and water quality along a Mekong tributary in Northern Lao PDR. Environ. Manage. 47 (2), 291-302.

Ribolzi, O., Evrard, O., Huon, S., De Rouw, A., Silvera, N., Latsachack, K.O., Soulileuth, B., Lefèvre, I., Pierret, A., Lacombe, G., et al., 2017. From shifting cultivation to teak plantation: effect on overland flow and sediment yield in a montane tropical catchment. Sci. Rep. 7 (1), 3987

Ribolzi, O., Patin, J., Bresson, L., Latsachack, K., Mouche, E., Sengtaheuanghoung, O., 
Silvera, N., Thiebaux, J., Valentin, C., 2011. Impact of slope gradient on soil surface features and infiltration on steep slopes in Northern Laos. Geomorphology 127 (1-2), $53-63$.

Roder, W., Phengchanh, S., Maniphone, S., 1997. Dynamics of soil and vegetation during crop and fallow period in slash-and-burn fields of Northern Laos. Geoderma 76 (1-2), 131-144.

Sidle, R.C., Gomi, T., Usuga, J.C.L., Jarihani, B., 2017. Hydrogeomorphic processes and scaling issues in the continuum from soil pedons to catchments. Earth Sci. Rev. 224, 75-96.

Sidle, R.C., Tani, M., Ziegler, A.D., 2006. Catchment processes in Southeast Asia: atmospheric, hydrologic, erosion, nutrient cycling, and management effects. For. Ecol. Manage. 224 (1), 1-4.

Sidle, R.C., Ziegler, A.D., Negishi, J.N., Nik, A.R., Siew, R., Turkelboom, F., 2006. Erosion processes in steep terrain - truths, myths, and uncertainties related to forest management in Southeast Asia. For. Ecol. Manage. 224 (1), 199-225.

Thongmanivong, S., Fujita, Y., 2006. Recent land use and livelihood transitions in Northern Laos. Mountain Res. Devel. 26 (3), 237-244.

Valentin, C., Agus, F., Alamban, R., Boosaner, A., Bricquet, J., Chaplot, V., De Guzman, T., De Rouw, A., Janeau, J., Orange, D., et al., 2008. Runoff and sediment losses from 27 upland catchments in Southeast Asia: impact of rapid land use changes and conservation practices. Agric. Ecosyst. Environ. 128 (4), 225-238.

Valentin, C., Bresson, L., 1992. Morphology, genesis and classification of surface crusts in loamy and sandy soils. Geoderma 55 (3-4), 225-245.

Valentin, C., Casenave, A., 1992. Infiltration into sealed soils as influenced by gravel cover. Soil Sci. Soc. Am. J. 56 (6), 1667-1673.

Van Dijk, A., Bruijnzeel, L., 2004a. Runoff and soil loss from bench terraces. 1. An eventbased model of rainfall infiltration and surface runoff. Eur. J. Soil Sci. 55 (2), 299-316.

Van Dijk, A., Bruijnzeel, L., 2004b. Runoff and soil loss from bench terraces. 2. An eventbased erosion process model. Eur. J. Soil Sci. 55 (2), 317-334.

Van Dijk, A., Bruijnzeel, L., Eisma, E., 2003. A methodology to study rain splash and wash processes under natural rainfall. Hydrol. Process. 17 (1), 153-167.

Van Dijk, A., Bruijnzeel, L., Rosewell, C., 2002a. Rainfall intensity-kinetic energy relationships: a critical literature appraisal. J. Hydrol. 261 (1), 1-23.

Van Dijk, A., Meesters, A., Bruijnzeel, L., 2002b. Exponential distribution theory and the interpretation of splash detachment and transport experiments. Soil Sci. Soc. Am. J. 66 (5), 1466-1474.

Vigiak, O., Ribolzi, O., Pierret, A., Sengtaheuanghoung, O., Valentin, C., 2008. Trapping efficiencies of cultivated and natural riparian vegetation of Northern Laos. J. Environ. Qual. 37 (3), 889-897.

Villatoro-Sánchez, M., Le Bissonnais, Y., Moussa, R., Rapidel, B., 2015. Temporal dynamics of runoff and soil loss on a plot scale under a coffee plantation on steep soil (ultisol), Costa Rica. J. Hydrol. 523, 409-426.

Wiersum, K., 1985. Effects of various vegetation layers of an Acacia auriculiformis fores plantation on surface erosion in Java, Indonesia. In: Soil erosion and conservation. Soil Conservation Society of America, pp. 79-89.

Yu, B., 2005. Process-based erosion modelling: promises and progress. In: Bonell, M., Bruijnzeel, L.A. (Eds.), Forests, water and people in the humid tropics: past, present and future hydrological research for integrated land and water management. Cambridge University Press, Ch. 33, p. 790.

Yu, B., Rose, C., Coughlan, K., Fentie, B., 1997. Plot-scale rainfall-runoff characteristics and modeling at six sites in Australia and Southeast Asia. Trans. ASAE 40 (5), 1295-1303.

Zhang, X.J., Wang, Z., 2017. Interrill soil erosion processes on steep slopes. J. Hydrol. $548,652-664$

Zhou, G., Morris, J., Yan, J., Yu, Z., Peng, S., 2002. Hydrological impacts of reafforestation with eucalypts and indigenous species: a case study in Southern China. For Ecol. Manage. 167 (1-3), 209-222.

Ziegler, A.D., Bruun, T.B., Guardiola-Claramonte, M., Giambelluca, T.W., Lawrence, D., Lam, N.T., 2009. Environmental consequences of the demise in swidden cultivation in montane mainland Southeast Asia: hydrology and geomorphology. Human Ecol. 37 (3), 361-373. 